\title{
Methodology for Gender Analysis in Transport: Factors with Influence in Women's Inclusion as Professionals and Users of Transport Infrastructures
}

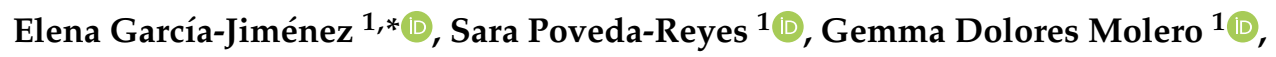 \\ Francisco Enrique Santarremigia ${ }^{1}(0)$, Andrea Gorrini ${ }^{2}{ }^{\oplus}$, Yvonne Hail ${ }^{3}$, \\ Augustus Ababio-Donkor ${ }^{4}(\mathbb{D})$, Maria Chiara Leva ${ }^{5}(\mathbb{D})$ and Filomena Mauriello ${ }^{6}(\mathbb{D})$ \\ 1 AITEC Research \& Innovation Projects, Parque Tecnológico C/Charles Robert Darwin 20, \\ 46980 Valencia, Spain; spoveda@aitec-intl.com (S.P.-R.); gmolero@aitec-intl.com (G.D.M.); \\ fsantarremigia@aitec-intl.com (F.E.S.) \\ 2 Systematica Srl, via Lovanio 8, 20121 Milano, Italy; a.gorrini@systematica.net \\ 3 Management Work and Organisation, Management School, University of Stirling, Stirling FK9 4LA, UK; \\ yvonne.hail1@stir.ac.uk \\ 4 Transport Research Institute. Edinburgh Napier University, Edinburgh EH10 5DT, UK; \\ a.ababio-donkor@napier.ac.uk \\ 5 School of food science and environmental Health, Technological University Dublin, Grangegorman lower, \\ D07 H6K8 Dublin, Ireland; mariachiara.leva@tudublin.ie \\ 6 Department of Civil, Architectural and Environmental Engineering, University of Naples Federico II, \\ Via Claudio 21, 80125 Napoli, Italy; filomena.mauriello@unina.it \\ * Correspondence: egarcia@aitec-intl.com; Tel.: +34-961-366-969
}

Received: 7 April 2020; Accepted: 29 April 2020; Published: 1 May 2020

\begin{abstract}
This work analyzes gendered processes by a methodology based on clustering factors with influence in the decision-making process of women as users or employees of the transport system. Considering gender as a social construction which changes over time and space, this study is based on the concept of a woman as a person who adopts this role in society. This paper performs a deep analysis of those factors women consider as needs and barriers to use or work in the transport system in four scenarios: railway public transport infrastructures, automated vehicles, bicycle sharing, and jobholders. A literature review and focus group discussions were performed under the consideration that the definition of woman includes the addition of several personal characteristics (age, sexual orientation, family responsibilities, and culture). The data analysis allowed the identification of fairness characteristics (FCs) that affect the interaction of women with the transport system for each scenario. A methodology for clustering the fairness characteristics identified the main areas of action to improve the inclusion of women within each use case. Further studies will be focused on the quantification and prioritization of the FCs through mathematical methods and the suggestion of inclusive measures by an interdisciplinary panel.
\end{abstract}

Keywords: fairness characteristics; clustering; decision-making process; public transport; bike sharing; employment; autonomous vehicles

\section{Introduction}

This work analyzes gendered processes by a methodology based on clustering factors with influence the decision-making process of women as users of and employees in the transport system.

Many studies have highlighted differences between men and women in their mobility patterns and participation in transport related jobs [1-5]. 
The use of public transport facilitates access for women to employment, education, and other services every day. In France, two-thirds of passengers on public transport networks are women [6]. Some of the explanations for this higher percentage of public transport use are the economic gap between women and men resulting from women's primary care roles and the impact this has on employment and environmental concerns [7-9]. Despite their high usage of the transport network, some women have suffered physical or verbal aggression, sexual harassment, or other forms of violence [6]. Harvey et al. [10] found that there are gender differences in the attitudes of women and men when travelling long distances or using high-speed rail in the UK. Some of the factors that show differences between genders were: women are more concerned with travel security than men, women perceive less than men the importance of high-speed rail prestige, and women also value their use of the travelling time more (it is important for them to do something when travelling). A similar study was developed by Dölarslan [11] with Turkish high-speed railway passengers and found that the association between customer satisfaction and loyalty behaviors was stronger for females.

In all European countries, fewer women than men own or use a car. Haboucha et al. [12] analyzed user preferences regarding autonomous vehicles in Israel and North America, and found that older people prefer using/driving regular vehicles than shared-autonomous vehicles (SAVs) or privately-owned autonomous vehicles. They also found that gender plays a significant role in the choice decision only for Israelis. In Israel, men are more likely than women to favor SAVs. This can possibly be explained by the fact that traditional gender differences are more prominent in the Middle East than in America. Similar results can be found in Europe. Payre et al. [13] analyzed the willingness of use and purchase of autonomous vehicles (AVs) of men and women from France and found that men want to use AVs and purchase them more than women. Other studies have also shown that younger people and men have a greater acceptance than women of autonomous vehicles $[14,15]$. In addition, Dourado et al. [16] analyzed driver behavior taking into account gender and concluded that men have more infractions and drive more aggressively, which affects the safety and security in our transport networks. Moreover, women are 25\% more likely to trip-chain [17]. Criado-Perez [18] added, "this figure rises to $39 \%$, if there is a child older than nine in the household", indicating that parental status also has impact on women's travel behavior.

There are currently around 1250 bike sharing systems with more than 10 million bicycles [19] which cover the multimodal gap between other modes of transport covering low to medium distances [19]. Several researchers have highlighted the low use of bike-sharing schemes by women and the need to increase their participation [20-22]. Stredwick [23] studied differences between men and women who used the schemes and reported that men cycle three times as often as women and travel more than four times as far. One of the barriers to use reported by women users of bike schemes are the unsafe driving conditions and need of more traffic rules and speed limits on public roads, with many claiming they prefer cycling in zones with lower traffic $[21,24]$. Use of bike-sharing schemes has been found to be regular for men while recreational journeys over weekends seem to be more dominant for female users [24]. In addition, some studies indicate that women are more likely to make multiple-circle bike sharing trip chains than men, especially on weekdays [25].

Differences in experiences of transport use and employment between women and men are based on a range of historical, social, cultural, economic, and, in some cases, physical factors. For example, in 2018 in the European Union, 26.5\% of women compared with $8 \%$ of men worked in a part-time job [26]; women also earned lower average wages than men, with a 2017 gender pay gap (difference between average gross hourly earnings of male and female employees as percent of male gross earnings) in EU-28 of $16 \%$ [27].

In 2015, in the United Kingdom, women made up 13\% of workers in the rail sector, of which only $2 \%$ were working as engineers and $66 \%$ were working in service positions [28]. Considering the transport system in general, the low percentage of women participating in transport related jobs has been attributed to a low percentage of women in engineering or transport related schools [29]; the impact of career breaks on women's professional life, due to, for example, maternity leave and 
child or elderly care responsibilities; and the fact that some transport jobs require long periods working away from home or have unpredictable work shifts or overtime which are not very compatible with the role of primary caregiver for children or with other family responsibilities [30].

What is Gender?

The term gender can often be misunderstood or misused and in many cases is conflated with biological sex when discussing differences between men and women. Both men and women are subjects of and subject to multiple local norms established across and within various cultures and societies in relation to their gendered identity, which makes it difficult to define males or females using biological characteristics only. Therefore, it is important to clarify what this term means for this work before going any further.

Hanson [1] defined gender as a socially constructed system of dynamic differences that change over time and space in contrast to other biological definitions that attribute immutable characteristics to men and women according to their biological characteristics. This dynamic connotation of women has been considered in this study.

Considering each woman is a sum of several intrinsic (age, gender, sexual orientation, ethnicity, religion, or disability) and non-intrinsic (family, education, or economic level) characteristics, it can be said that all of them, in the same way as men, are polyhedral individuals (PI) [31]. As this work is focused on the transport system, it could be said that a PI is a user or employee in this sector and that the set of characteristics of each individual influence the behavioral patterns in the transport system. The combination of the different characteristics that constitute the "profiles" are of vital importance in the analysis of the decision-making process, especially for vulnerable groups of women.

Identifying the needs and barriers women face as users and employees of the transport sector will allow the determination of a series of factors, called fairness characteristics (FCs), which are fair to men and women by including aspects of justice, equity, and equality (of opportunity and of outcome) [32-34]. Within this study, fairness was defined as a state in which people are treated similarly, unimpeded by prejudices or unnecessary distinctions or barriers, unless they can be explicitly justified. Therefore, FCs are based on those aspects that all female users find important for a comfortable, safe, and useful service or for inclusive and fair employment in transport.

Since the transport system is very broad and complex, this study is focused on four specific scenarios, also called use cases: (I) railway public transport infrastructures; (II) autonomous vehicles; (III) bicycle sharing; and (IV) employment. The four use cases were selected for two main reasons: (i) they are use cases that, based on the literature, have long-term inequality issues with regards to gender and use; and (ii) authors' professional experience on these topics.

Previous literature has identified some of the aspects influencing the inclusion of women in each of the four use cases. However, although we know that there are cases of gender inequality in all four of the use cases developed by DIAMOND, there are also important gaps in current research with regards to how different groups of women experience inequality across multiple transport modes as both users and employees. This research therefore fills that gap in knowledge by developing an analysis based on the different types of experiences faced by a variety of groups of women dependent on their age, geographical location, disability, ethnicity, etc. The findings are then utilized in a DIAMOND fairness toolbox to support transport companies, regulatory institutions, and stakeholders in delivering a fair system of public transport for women as users and employees.

This paper uses data collected from the European Union Horizon 2020 funded DIAMOND project, to help improve the design of public transport infrastructures, services, and vehicles and improve guidelines for fairer employment in the transport sector for women.

The methodological aim of this study is to identify and cluster a series of FCs related to the four different use cases described above as a first step in further developing measures to increase the inclusion and equal treatment of women in the public transport sector.

Section 2 introduces the overall methodology designed to obtain FCs related to each of the four use cases, before providing a detailed description of how the methodology was operationalized to 
identify the FCs. Section 3 introduces the results and discussion, presents the FCs and the hierarchical model of FCs for each transport scenario or use case, and the hierarchy that will be helpful for future analysis using for example the analytic hierarchical process or other-decision making methods to evaluate priorities. Finally, the conclusions can be found in Section 4.

\section{Methodology}

Figure 1 briefly shows the general methodology established within this paper for the definition and clustering of FCs for each use case with the aim of improving women's inclusion in the transport system. The methodology used for the development of the thematic analysis follows the guidelines and steps defined by Braun and Clarke [35], which are based on familiarizing with the data, generating initial codes (FCs), searching for themes (CFCs), reviewing themes, defining and naming themes, and producing the report.

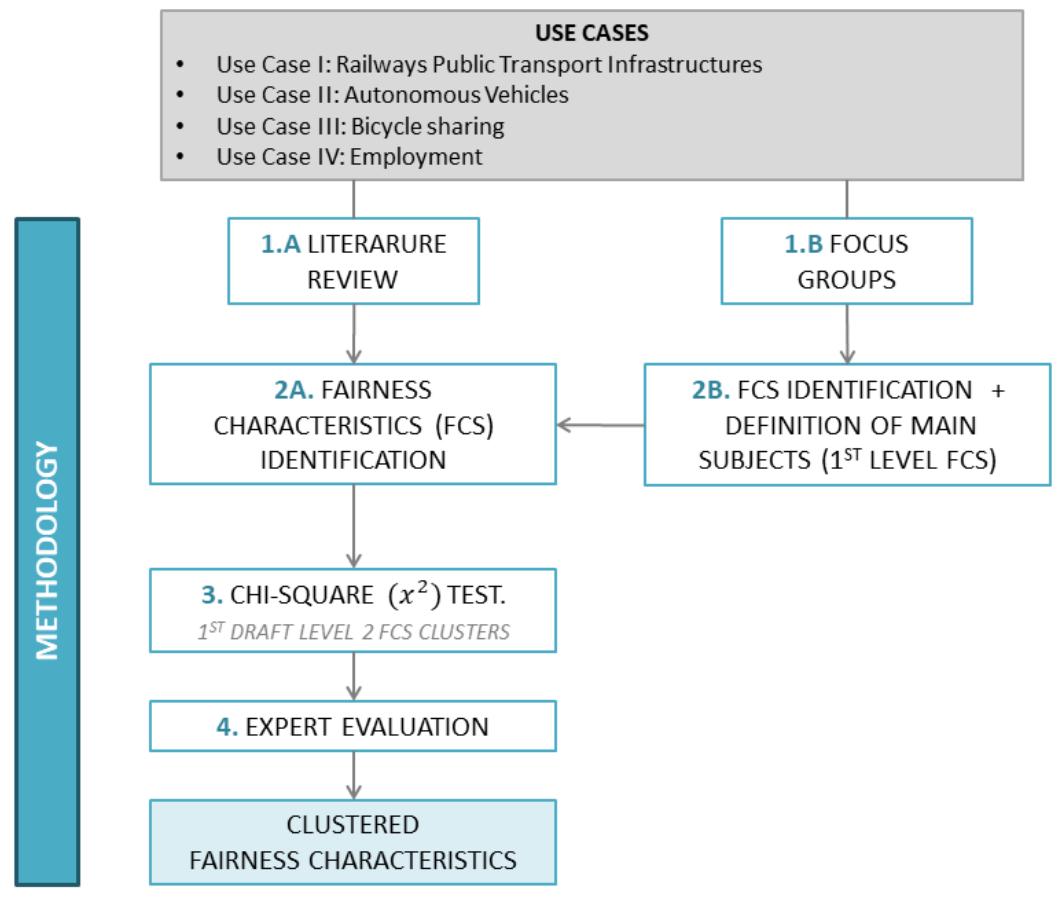

Figure 1. General methodology.

The modeling approach for the four use cases can be broken down into four key steps:

1. Familiarizing with data: The first step began with a literature review (1A) and focus groups (1B) to understand the variables related to notions of fairness that women as users and employees of the transport system consider representative in the four scenarios.

Due to time constraints, it was not possible to conduct a full systematic review as per either the Cochrane or Joanna Briggs Institute (JBI) frameworks and we therefore conducted a scoping review of current literature. Scoping reviews are mainly utilized to provide a descriptive overview of a corpus of literature when there is limited time and/or resources available to conduct a full systematic review and the topic under review is a new concept [36]. Scoping reviews are mainly utilized to examine and map the range of research in a specific area and to identify research gaps in the existing literature [37]. It is also claimed that utilizing a scoping review to explore the wider academic literature provides additional value particularly when authors are looking to produce "evidence to inform practice" [38] as we are in this paper, rather than collating empirical evidence. A scoping review is also suitable as we are not looking to "produce a critically appraised and synthesised result/answer to a particular 
question" [38] but to map and identify current research which examines the barriers and facilitators to women using public transport.

Scoping reviews as a method of literature review employ many of the same processes as systematic reviews; they both use rigorous and transparent methods to identify the relevant literature pertaining to a research question [36]. The framework for conducting a transparent and rigorous scoping review listed by Arksey and O'Malley [39] has the following steps: identifying the research question; utilizing wider search terms than typically used in a systematic review to gather a wider range of literature; identifying relevant studies; study selection; charting the data; collating; summarizing; and reporting the results.

Following this framework, search terms were identified to be used in the literature search and to support the inclusion and exclusion criteria that would be used to distinguish documents of relevance. The inclusion framework for documents for this paper was based on:

- English language documents

- Both qualitative and quantitative research methodologies

- Publication date 2000 or later

- A focus on sex and/or gender in relation to transport users

- Field work being conducted in Europe, North America, Australia, or New Zealand, as the main interest is in the EU

- Relevance to the EU context for the identification of FCs

- The exclusion framework included:

- Papers where the fieldwork was conducted in developing countries

- $\quad$ Papers published before 2000

In addition, some other papers were identified using expert knowledge and contacts. Some exceptions were made for some papers dating before 2000 due to their relevance to the topic.

The literature review was developed through a review of peer reviewed and conference papers available via the Scopus, Web of Science, Mendeley, Google Scholar, ResearchGate, and EU official (e.g., website of the Directorate-General for Mobility and Transport), as well as databases that focused on women and the transport modes/employment used in the four use cases.

The search terms used in each use case for a first search were:

- Use Case I: women, gender inclusion, public transports, railway, universal design.

- Use Case II: gender, autonomous vehicles, driverless, safety, comfort, human-machine interface.

- Use Case III: gender, bike share, bicycle sharing, barriers to bike share, active travel, women and bike share.

- Use Case IV: women, gender, fairness, employment, transport, equality, equity, public transport, transport planning, fair, employment opportunity.

Numerous papers were identified for each use case and in order to refine the number the first step was to eliminate duplicates. From the remaining list, abstracts and conclusions were checked for inclusion and exclusion criteria to obtain the final list of papers, which were reviewed to identify the FCs. After the identification of a first list of FCs, these FCs were used as keywords for a second analysis or iteration of the literature and saturate the structure of the thematic analysis.

Two focus groups were developed in Dublin, one group of 18 participants representing transport users and another group of 18 participants representing transport employees. Participants for the focus groups on users of public transport were recruited sending an email or invitation to the college community, a representative of the national transport and infrastructure authority, representatives of special needs and disability association in Ireland, a cyclist association, and transport customer associations. Participants for the focus group related to fairness for employability in transport were recruited by email invite to representatives from the major transport and rail service providers in Dublin and the transport and infrastructure authority. Invitations were sent with attached information about 
the project, the scope of the research and a briefing about the terms and conditions of the voluntary participation of participants asking them to complete a consent form and provide an indication of their availability for the different time slots allocated to the different focus groups. The process was developed in accordance with the approved protocol agreed with the research ethic university committee. The majority of the sample was female (88\%), aged $18-25(38.9 \%)$, and white Irish $(77.7 \%)$. The sample included older women, disabled women, and black Irish women. Focus groups were conducted by experienced interviewers and by native speakers. Each participant was provided with an informed consent form to complete which asked their permission to record the group discussion, the aim of the study, a statement of anonymity and confidentiality, details of data storage plans and access, and a reminder that their involvement is completely voluntary. Both focus group sessions began by asking participants to complete a demographic questionnaire prior to the main discussion to enable the needs of specific users and employees to be established and also assisted in developing themes from the findings. Focus group discussions were organized under the themes "Characteristics, Needs, and Barriers" based on the literature available. Notes were taken of the comments made by participants under each of these headings. Measurements of the characteristics, needs and barriers of both transport users and transport employees were taken using the attitudinal surveys and focus group data. The surveys prepared for each focus group included:

- In the user's questionnaire, participants ( $\mathrm{N}=18,2$ males, 16 females) were asked demographic information. Participants were asked about their usual travel to different places (e.g., supermarket, park, and post office) ranging from on foot to taxi, and were asked to provide their reasoning. Needs and barriers of future scenarios using autonomous vehicles were also discussed. Participants were asked to also indicate their main way of transport; thinking of this, participants then rated their safety and security and public transport needs and barriers ranging from $0=$ "Entirely Disagree" to $6=$ Entirely Agree. Finally, participants rated their experience of inclusiveness and fairness ranging from $0=$ "Entirely Disagree" to $6=$ "Entirely Agree".

- In the employment questionnaire, participants ( $\mathrm{N}=18 ; 2$ males, 16 females) were asked to complete demographic information, including their transport sector (e.g., tram and train), job title, and job level. Participants were asked to rate how much they agreed with three different definitions of inclusion and fairness on a scale of $1=$ "Strongly Disagree" to $7=$ "Strongly Agree", and also to include their organizational approach and their definitions of inclusion and fairness. Participants were asked to rate their career needs in the pursuit of their career (e.g., mentoring, role models, and flexible working hours) on a scale of $1=$ "Not at Important" to $7=$ "Very Important"). Participants were asked to consider whether certain career barriers would hinder the pursuit of their career covering a range of dimensions, e.g., racial discrimination and sex discrimination. Items were adapted from Swanson's Career Barriers Inventory-Revised (CBI-R) rated on a scale $1=$ "Would not hinder at all" to $7=$ "Would completely hinder". Participants were finally asked whether they thought their gender impacted their duties or tasks (yes/no) and were asked to elaborate on this in an open-ended comment.

Two focus group pilots (one focus group with six people for the users' focus group and one focus group with six people for the employees' focus group) were developed to refine the questionnaires and discussion themes. It should be noted that two focus groups of only one region are not representative of the whole Europe. However, they are useful for the purpose of this paper, the definition of main areas of discussion with notions of fairness, called afterwards first level FCs or clusters of fairness characteristics (CFCs). 
2. Generating initial codes (FCs and CFCs names): After completion of the thematic analysis and focus groups: (i) It was possible to create a list of FCs that have influence on women's experiences and/or inclusion in transport (2A and 2B); for this purpose, the FCs that appeared in each paper reviewed were identified (see Tables 1-4, for Use Cases I-IV, respectively). (ii) The focus groups also helped in the definition of the main subjects or areas that the literature and transport users and employees considered important for a fair transport system (2B). These main subjects or areas identified for each use case are what we call first level FCs.

3. Searching for themes - Collating codes into potential themes: The FCs identified through the literature review for each use case (see Tables 2-4) were grouped in clusters within each Level 1 FC defined in the previous step by performing a chi-squared test $\left(\chi^{2}\right)$ [40]. The chi-square test is used to determine if there is a significant relationship between two nominal (categorical) variables, in this case FCs. The null hypothesis for this test is that there is no relationship between $X$ and $Y$ variables. The alternative hypothesis is that there is a relationship between the variables. In this test, the frequency of each FC is compared across the other FCs. Let $X$ and $Y$ be two categorical response variables or FCs, $\chi^{2}$ is determined by the relationship:

$$
\chi^{2}=\left(a-\frac{e \times g}{n}\right)^{2}+\left(b-\frac{e \times h}{n}\right)^{2}+\left(c-\frac{f \times g}{n}\right)^{2}+\left(d-\frac{f \times h}{n}\right)^{2}
$$

where $a, b, c$, and $d$ represent the frequencies of observation (see Table 5). The $p$-value for this test statistic is based on the chi-square probability distribution.

Therefore, the null hypothesis is rejected if the p-value is less than significance level, called $\alpha$. In this work, there are two significance levels defined: $\alpha=0.10$ and $\alpha=0.20$.

- For $p$-value $\leq \alpha=0.10$, the variables $X$ and $Y$ are strongly dependent, which corresponds to a confidence level $\geq 90 \%$.

- $\quad$ For $\alpha=0.10>p$-value $>\alpha=0.20$, the variables $X$ and $Y$ are moderately dependent, which corresponds to a confidence level between $80 \%$ and $90 \%$.

This analysis allows the development of a first draft of groups or clusters of aspects or FCs that were identified as important for the development of a fair transport system by the definition of which variables or FCs (Level 2 FCs) should go within each main area (Level 1 FCs or CFCs) identified through the focus group sessions.

4. Reviewing themes, defining, and naming themes: Experts evaluate the consistency of the results obtained in the $x^{2}$ test; for those variables or FCs that the chi-square test shows could pertain to two different clusters, the experts decide in which cluster it is more appropriately included. Thematic maps were also used to synthesize ideas, organize data, and name the main themes identified.

5. Final analysis of the results and development of the report. This report includes a hierarchical tree formed by FCs into two levels (Level 1 (CFCs) and Level 2), and their definition and aspects to be highlighted for each of the use cases. The development of a hierarchical tree is useful for further data gathering and analysis using for example multicriteria decision making methodologies such as the analytic hierarchy process for obtaining the weight and the establishment of priorities; methods that have been widely used in several types of studies [41-44].

\section{Results and Discussion}

The data gathered from Step 1A. Literature review and Step 1B. Focus Groups tools, allowed the definition of a list of FCs for each use case, their analysis using $\chi^{2}$ test and the identified CFCs is analyzed in the next subsections for each of the use cases. 


\subsection{Use Case I. Railway Public Transport Infrastructures}

The objective of this use case is to investigate women's needs as users of metro and urban railway public transport to further develop gender-equitable transport planning policies and increase the percentage of women using public transport services.

After performing the literature review and the focus groups, taking into consideration the objective of this scenario, three CFCs or Level 1 FCs and nine Level 2 FCs were identified (Table 2).

To determine the relationship among the different identified factors, the chi-squared $(\chi 2)$ statistical tests was used to show that there are appreciable dependences among the 81 FCs with $p$-value $<0.20$, corresponding confidence level $>80 \%$. Table A1 (Appendix A) shows the results of the chi-squared $\left(\chi^{2}\right)$ test for Use Case I.

Results from the statistical tests and the evaluation by the experts determined that the appropriate FCs within each cluster are the ones shown in Figure 2.

Table 1. Literature review of Use Case I: railway public transport infrastructures.

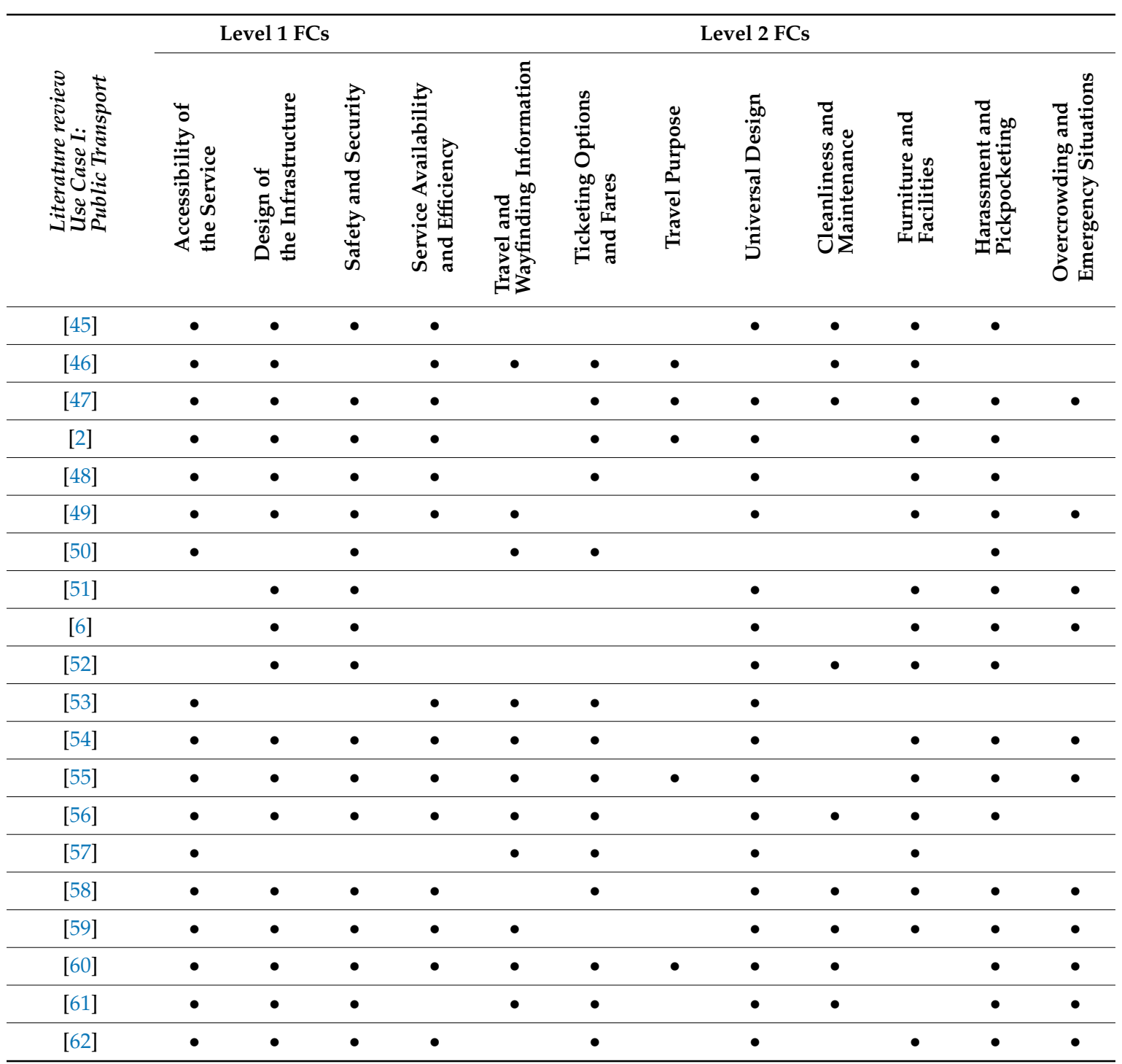

The first CFC is related to the "accessibility of the service" and is based on women's perceptions of the operational details and quality of service provided. To ensure that the metro and commuter rail service is useful, the "service availability and efficiency" FC is of vital importance, especially in suburban neighborhood, as stations are connected with other modes of transport to reach different places: 
residence, work, childcare facilities, and shops [2]. The accessibility of public transport infrastructure also includes receiving real-time information regarding the operation of the service and information for easy wayfinding [54]. This FC is called "travel and wayfinding information provision". Participants in the focus group when talking about this theme indicated their interest in real-time GPS apps as a tool to increase the use of public transport by women. It is recognized that many of these issues will also apply to men using public transport systems, but they are particularly relevant to women.

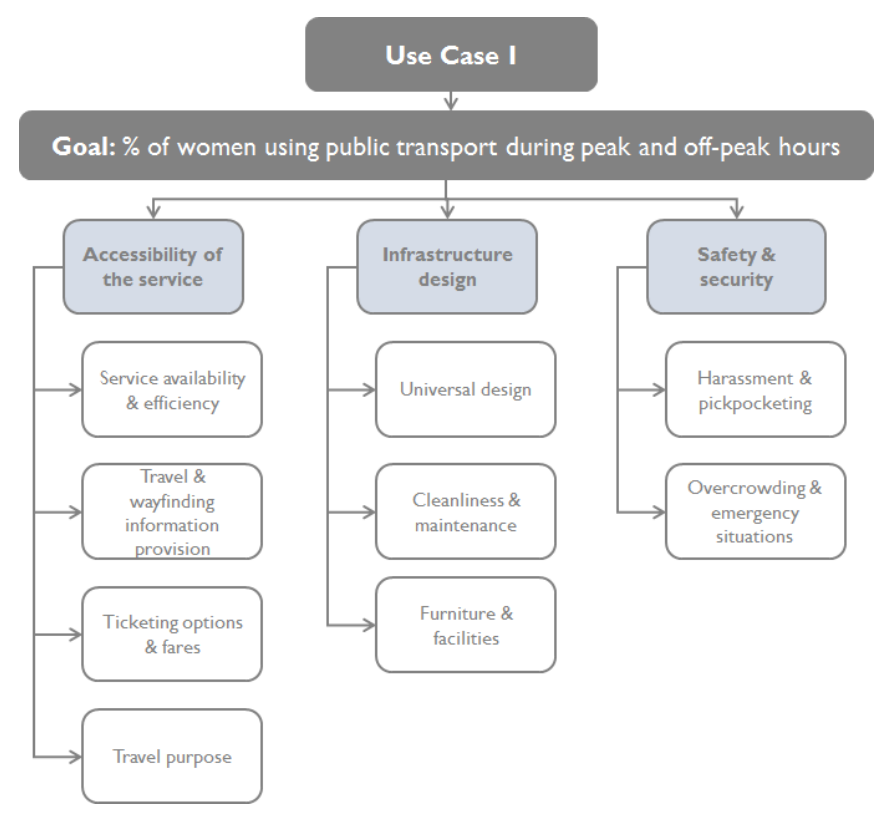

Figure 2. Hierarchy of fairness characteristics for Use Case I.

Two further aspects influence the accessibility of the service: Firstly, economic factors such as "ticketing options and fares" include gender issues in transport tariff policies, flexible tickets, and discount fares. Participants from the focus groups disagreed with the statement "The cost of travelling on public transport is not a problem for me" (Mean $=2.33, \mathrm{SD}=1.82$ ). Secondly, different "travel purpose" categories also influence the choice transport mode for women for using public transport (e.g., if a railway station is not easily accessible for women travelling with children, they will not use it for shopping unless it is totally necessary) [63].

The second CFC determines the needs and barriers expressed by women in relation to the "design of the infrastructure". This cluster is focused on the architectural and design characteristics, facilities provided, and maintenance based on their perceptions while using these public infrastructures. A factor that affects the use of a means of transport is its "universal design", which refers to the design and composition of an accessible environment that can be used by all people regardless of their age, size, ability, or disability. This factor encompasses such aspects as the presence of lifts, escalators, and some other items that facilitate the movement of all people, but especially disabled people and those who are carrying things. Other aspects linked with the design of the railway transport system that contribute to making a more comfortable experience are the "furniture and other facilities" provided to accommodate women and the other people they accompany (children and the elderly) and the "cleanliness and maintenance" level, including clean toilets, keeping the infrastructure in good condition, avoiding graffiti and vandalism, or having recycling waste baskets. Participants of the focus group disagreed with the statement "The availability of bathroom facilities meets my needs" (Mean $=2.31$, $\mathrm{SD}=1.88$ ).

The third and last cluster that influences the use women make of the railway transport system relates to the "safety and security" aspects. Women can be subjected to physical victimization, harassment, stalking, sexual assault, or rape when using transport services $[6,60]$. Thus, they are 
sometimes fearful of certain transit environments and frequently adjust their travel patterns to avoid "harassment and pickpocketing" [52,55]. Increasing the presence of police and security personnel or boosting the number of CCTV systems could be one measure to encourage them to use public transport.

"Overcrowding and emergency situations" also reduces women's perception of personal safety and security [59]. Offering more personal space and improving ventilation will diminish negative feelings for women and will benefit their use of this transport system.

In line with these findings, the data collected from the focus groups highlighted that current needs for women regarding safety and security issues were: staff visibility, CCTV, lighting, quick response, staff at all stations, some places unmanned, room for belongings to be located nearby, text alert available to alert about anti-social behavior, and signage to inform passengers about safety text number and safety for staff.

\subsection{Use Case II. Autonomous Vehicles}

The National Highway Safety Administration (NHTSA) organizes vehicle automation into six levels, ranging from Level 0 vehicles without any automation to Level 5 of fully automated vehicles [64]. The objective of Use Case II is to investigate the acceptance of autonomous vehicles of Level 4 (i.e., the Automated Driving System (ADS) can perform by itself all driving tasks and monitor the driving environment in certain circumstances) and Level 5 (i.e., the ADS can do all the driving in all circumstances) by women as users of the road.

The literature review and the focus group data allowed the identification of five CFCs of Level 1 and 20 FCs of Level 2 (see Table 3). In the same way as Use Case I, after an identification of the FCs, the statistical results show that there are appreciable dependences among the 249 characteristics that indicate which FCs belong to each cluster (see Table A2 of Appendix A).

Results from the statistical tests and the evaluation by the experts determined that the appropriate FCs within each cluster are the ones shown in Figure 3.

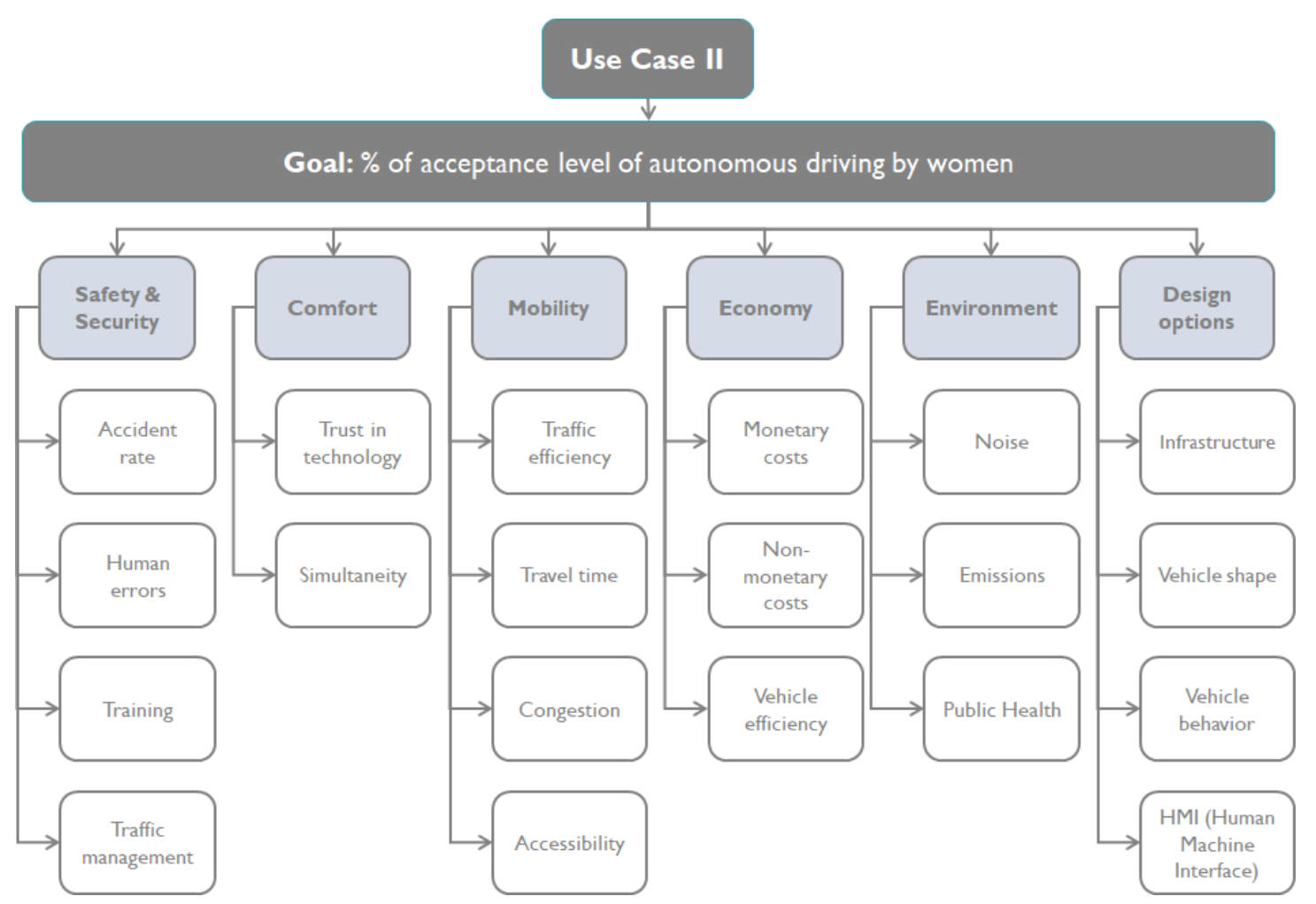

Figure 3. Hierarchy of fairness characteristics for Use Case II. 
Table 2. Results of literature review for the Use Case II: autonomous vehicles.

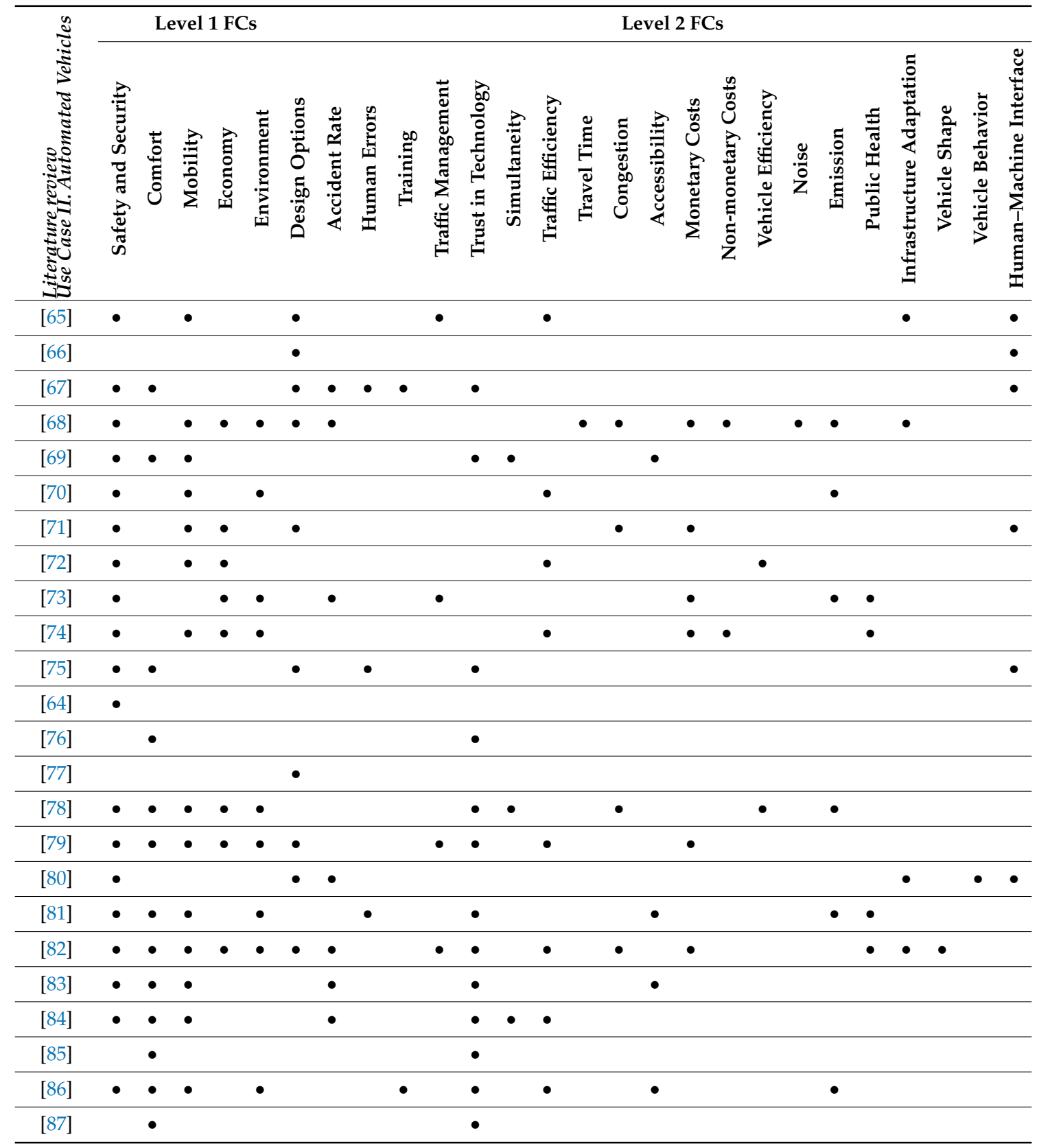

The first CFC "safety and security" is focused on people not feeling any risk while they are driving an autonomous vehicle (AV). One of the main concerns is reducing "accident rate" on roads, AVs have the potential to reduce car accident rates and deaths. Around $90 \%$ of current road traffic accidents are attributed to "human errors" [70]. It is claimed that AV will benefit road users by introducing a safer and more efficient transport system without driver control that will considerably reduce the risk of accidents and traffic jams. Traffic at conflict points will be synchronized, leading to a more homogenous traffic flow [72]. Participants of the focus group addressing autonomous vehicles indicated one of their main concerns was the uncertainty about the safety of these new type of cars. While in the future they could prove to be a safer transport system, participants indicated that currently the perception is that they are not as safe as conventional cars.

The data indicate that there are two ways to influence safety and security in AVs in situations where driver control is required: (i) providing AV specific training for owners; and (ii) introducing 
new policies transport management policies which take account of the different automatization levels driving in the same infrastructure.

Regarding the "training" FC, drivers need to be sufficiently skilled to be able to take over control if needed [67]. A standard routine for control transitions in automated vehicles should be part of the transition training in order to perceive, understand, and act appropriately upon the provided information [67].

Considering the "traffic management" FC, it is recommended that policy makers should carefully plan the transition from the current situation to include AVs in order to avoid any negative consequences [73]. In the initial phase, public authorities are acting as enablers by providing the framework in which industry and operators can deploy new technologies and systems. In future scenarios (especially in the event of substantial increases in travel demand), traffic management policies would need to play a decisive role in enabling safe and efficient mobility [73].

The second CFC is focused on the feeling of "comfort" women experience while driving an AV when the vehicle has control (in Levels 4 and 5). This FC is related to "trust in the technology" that controls the AV. Participants in the focus group session also highlighted factors which they perceived would influence the future acceptance of autonomous vehicles for both women and men based on trust towards the system's capabilities under different situations (weather conditions, speed, and driving style), communication between self-driving cars, with one participant claiming "People are unsure how it can work if there is no driver sitting behind the steering wheel. They prefer to rely on themselves." In addition, high automated levels will allow drivers to do other things, such as reading a book or responding to an e-mail, while the vehicle drives by itself ("simultaneity").

Another CFC that was shown to encourage an increase in acceptance of AVs by women is "mobility". Mobility is related to AVs being more "efficient in traffic". Driving more densely and increasing the capacity of roads results in saving "travel time" by adjusting the travel patterns to the particular situations of the traffic. The consequence of a more efficient traffic and systems such as the green wave (green wave: turning lights to green when cars circulate as much as the maximum speed and find them in red when they drive at higher speeds, forcing drivers to stop) will help in reducing "congestion" and traffic jams. On the other hand, some participants on the focus group indicated that AV speeds may be slower than conventional cars, and that one may expect AVs to reinforce (and perhaps even magnify) existing gender differences in commuting (women are more likely to make trip chaining vs. men who usually commute from A to B). Another important mobility aspect related to AVs is the claim that everyone, including older people, the disabled, and people without driving licenses, could own an AV because they will not need to drive in the more traditional sense of being in complete control of the vehicle, thus increasing the potential ownership of AVs across populations ("accessibility" FC) $[68,73]$.

The CFC "economy" is focused on the influence of AV on: (i) "monetary costs", such as saving fuel, the costs of the new technologies, and the increasing price of these advanced vehicles; and (ii) "non-monetary costs", such as saving time on private and work trips, increasing traffic safety, losing driving skills, and reducing environmental impacts.

It is accepted that costs have an influence on the economic factor of AV ownership, but there is another factor, "vehicle efficiency", that should also be considered and includes energy consumption, energy efficiency, and predictive driving strategies [65]. Drivers of automated vehicles it is argued will improve fuel efficiency due to convoy driving (platooning) and smoother driving [68]. In addition, since traffic at conflict points will be synchronized, the traffic flow will be more consistent [72].

The CFC "environment" is traditionally related to "noise" and "emissions". Both factors will be reduced by $\mathrm{AV}$ through smoother acceleration and deceleration driving patterns. This was also highlighted in the focus group session "More smooth acceleration/deceleration will produce less emissions" and "AV will reduce emissions due to less fuel consumption and traffic optimization". Automation may also have an impact on "health" (physical and mental) of individuals and entire communities, via improved road safety, a reduction in air pollution, an ability to increase walking and 
cycling, together with improving access to medical care, food, employment, education, and recreation for those who do not have access to traditional cars [88]. Participants of the focus group sessions also indicated that $\mathrm{AVs}$ could reduce the pressure associated with driving in stressful scenarios such as peak time morning transport meaning users will arrive at their destination relaxed.

The last CFC is "design options", which is focused on alternatives that address particular design problems for women. "Infrastructure adaptation" to new technologies in order to connect the car with transport infrastructure will make it possible to drive vehicles in the last level of automation. In addition, focus group participants indicated that connectivity should allow for in-vehicle internet services and for vehicles to be able to communicate with each other or the external infrastructure system to inform drivers of the most appropriate speed to safely and comfortable merge with the motorway traffic. Another design adaptation option will be the "vehicle shape". AVs should be designed in such a way to support comprehension of the vehicles' driving mode and make it identifiable as an AV opposed to non-autonomous vehicles.

An adequate design of "vehicle behavior", such as an indication of the vehicle's intention to accelerate, decelerate, or change direction, will provide other traffic participants with the ability to recognize maneuvers, which is especially critical in shared spaces with both AVs and non-automated vehicles. The appropriate design of vehicle maneuver systems will also influence the behavior of surrounding traffic participants and increase traffic efficiency and cooperation [89]. Vehicle movements might also be used by other traffic participants to interpret if they have been detected. For example, if the automated vehicle slows down when approaching a zebra crossing, other traffic participants might assume that it will stop [77]. Focus group discussion indicated that AVs could avoid suboptimal behavior such as inappropriate time headways and speeds.

To make AVs possible a "Human-Machine Interface" (HMI) is required to transfer relevant information to the driver using visual or acoustic communication channels. Visual information can either be sent in the form of text messages, icons, or light patterns displayed in the vehicle or projected on to the road in front of the vehicle. While visual signs in the form of lights might be used to inform other traffic participants about the vehicles driving mode and maneuvers, visual text messages or icons could be used to address only one specific recipient and provide advice on ensuing actions [77]. Focus group participants also discussed HMI and claimed that it should assist drivers in usual driving and in critical situations. However, they also claimed that drivers of AVs should know how to interact with it, and that the interfaces used should be similar across AV manufacturers.

\subsection{Use Case III. Bicycle Sharing}

The aim of this use case is to investigate the mobility needs and challenges of women in relation to bike sharing services in order to produce guidelines for providing more inclusive infrastructure, improve planning and distribution of docking points, engender fair inclusion for women, and address the social imbalance with this aspect of transport. Therefore, the final goal of this use case is to identify and remove the barriers preventing women from using bike sharing services and, then, to increase the percentage of women using bike sharing services to meet their mobility needs.

The literature review and focus groups allowed for the identification of four CFCs and 18 FCs (see Table 4) related to bike sharing schemes. As in previous use cases after identifying the FCs, the statistical results showed that there were significant dependences among 201 FCs that indicated which factors belong to each cluster (see Table A3 of Appendix A).

Results from the statistical tests and the evaluation by the experts determined that the appropriate FCs within each cluster are the ones shown in Figure 4. 
Table 3. Results of literature review for the Use Case III: bicycle sharing.

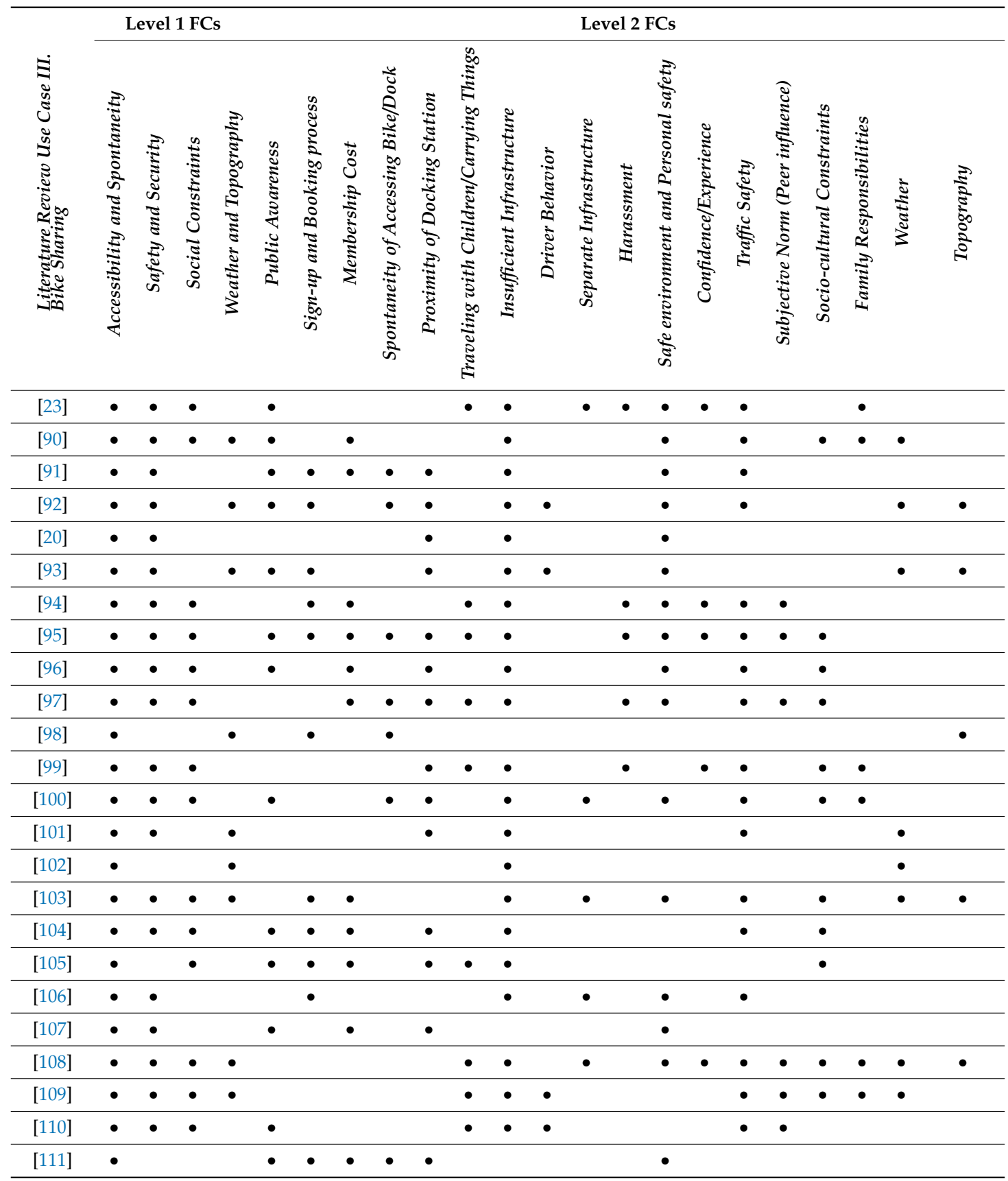

The first cluster of fairness characteristics "accessibility and spontaneity" is related to all of those aspects that influence how easy it is to access a bike when needed to meet the flexible mobility needs of women. There are different factors or FCs that are included within this concept. "Membership cost" is a major consideration when evaluating the aspect of inclusivity of shared transport schemes, including: entry costs, high rental costs when used for more hours every day, accessories cost (helmet, clothing, etc.), and the fear of liability resulting from overage fees, damages, and theft of the bike $[20,90,103,105,107]$. Fair access to bike share schemes for people on low incomes is also an important factor when using this transport scheme. This has been defined by the FC "sign-up and booking process". Bike sharing users have also highlighted that there are occasions when there are no vacant docks for drop off bikes or an availability of bikes at bike-sharing stations, which discourages them from using the bike sharing systems and therefore they use other modes of public transport. 
This barrier has been defined as the FC "spontaneity of accessing bike/dock". Focus group participants also highlighted the importance of bike sharing schemes as providing good connectivity between different transport types and the importance of waiting times, claiming the use of bikes could be boosted if the availability of bikes was assured and using the bike was more efficient than taking the bus for example. Additionally, the location of bike docking stations is also important in relation to spontaneity and access with claims that currently most bike stations are concentrated in city centers, leaving peripheral areas or neighborhoods with limited or no access to this type of service [91]. Location of docking stations was also discussed in the focus groups with suggestions made that there needs to be more communication with all communities, therefore FC "proximity and convenience of docking stations" is identified as a key issue when analyzing the usage and inclusion of bike sharing within society.

\section{Use Case III}

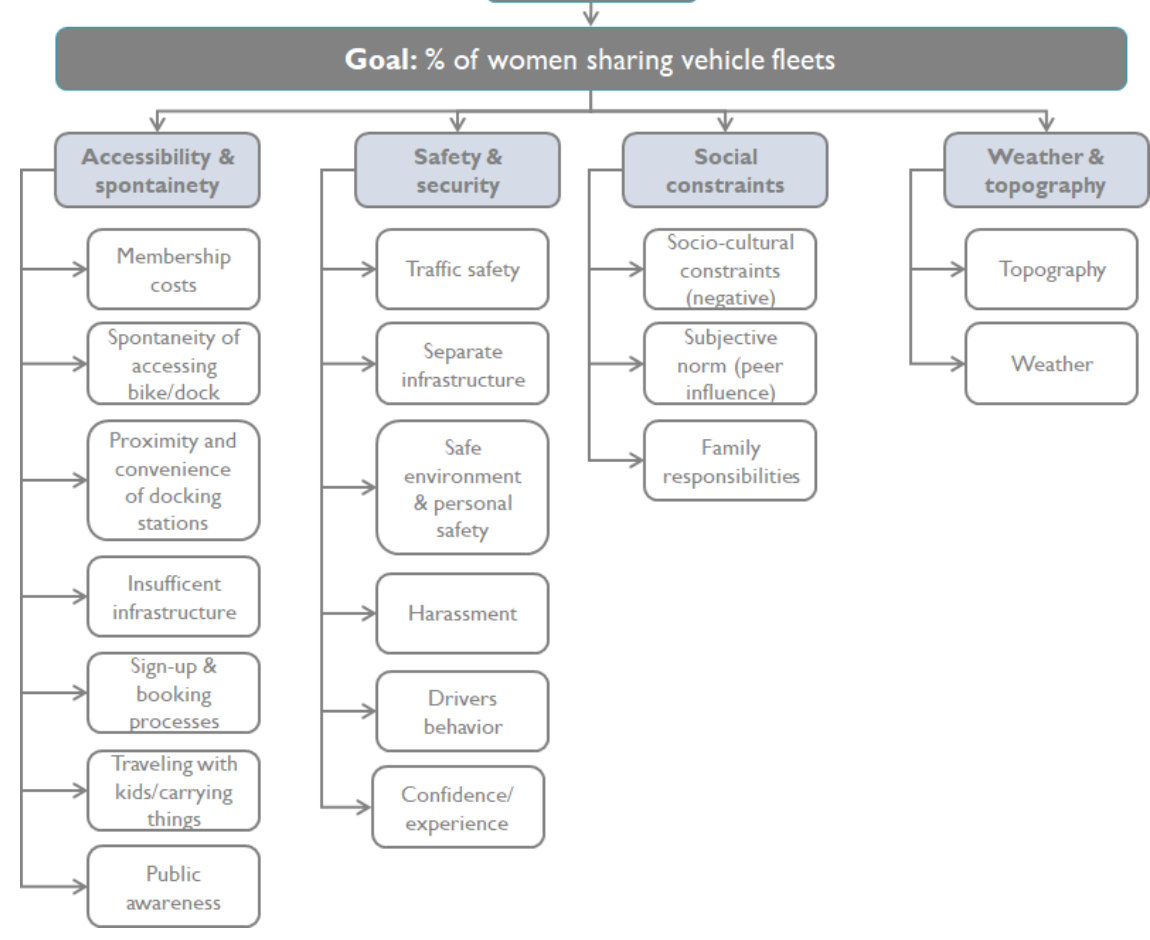

Figure 4. Hierarchy of fairness characteristics for Use Case III.

A further FC relates to the need for an appropriate bicycle infrastructure, and is identified as FC "insufficient infrastructure". Lack of adequate and attractive bike-share infrastructure, including cycle paths and cycle facilities (e.g., changing/toilet facilities), are identified as barriers to women's use of bike share and cycling in general $[23,100]$. Women often travel with children or are carrying things such as shopping, therefore a further FC is identified as "traveling with children and carrying things"; however, available bike sharing schemes are not always adapted to these circumstances, for example through the provision of bike child-seats, trailers, and other children's cycling equipment [23]. The literature also suggests that the lack of time, trip-chaining, and level of education attainment are also barriers to women (and mothers) wanting to cycle [2]. The "Public awareness" FC highlights this and suggests that there is currently a low level of awareness of the benefits of cycling. In fact, studies have shown that low-income and minority groups rarely travel outside their immediate location and not all are aware of local cycling routes [23,90].

The second CFC is related to "safety and security" factors. It is focused on issues and factors influencing women's perception of danger and insecurity while cycling and using current bicycle infrastructures. One of the FCs affecting safety and security is "traffic safety"; this factor is related to the fear of being hit by a vehicle. Women feel more intimidated by vehicular traffic than men, and 
this emerges as the top deterrent to cycling among women $[23,105]$. This safety issue that links safety with traffic raises the need for a second FC, the development of a "separate infrastructure", for bikes such as a cycle path, to increase the safety of bike users, especially women $[23,100]$. People should feel safe and secure all the time, not only when riding their bicycle. Stations should be appropriately designed to address gender issues and protect users from criminals, for example, by providing security cameras or adequate lightning. This was supported by findings from the focus group data which show that participants believed that all transport users, no matter their mode of choice, should feel safe when accessing or using it and put forwards recommendations based on a good lighting and security cameras, and an easy and fast reporting system for anti-social behaviors. This FC has been defined as "safe environment and personal safety". "Harassment" is also a factor affecting women when using shared bicycles. Female cyclists have reported sexual harassment from other road users, and their fear in such situations can be a significant barrier to their use of bike sharing [94,99]. In line with this, the level of awareness and respect shown by drivers towards cyclists (FC "driver behavior") is found to be significantly lower than desired, posing a danger to cycling [92,93] and a barrier to bike sharing. The previous experiences of cyclists on the roads has also been shown to be an important factor when choosing one mode of transport or another (FC "confidencelexperience"). Women are more likely than men to describe themselves as "inexperienced cyclists" [23,99], indicating that there is a gendered confidence issue with cycling raising an awareness of the need for women to overcome fear and anxiety about being on the road with traffic.

The third CFC is related to "social constraint" factors. Social constraints include the embedded perceptions and cultural stigmatization associated with cycling and bike sharing that fuels the perception that cycling is for the poor. People surrounding you have a high influence on the decision to cycle and bike share. In addition, some women give more importance to their appearance than some men, not wanting to arrive at work messy due to cycling [110]. These factors, driven by the perception of what other people might think or the influence of what is perceived as a norm in surrounding society, have been defined as FC "subjective norm". The perception of cycling as a negative activity and as something only for low-income people [99] is included within the FC "socio-cultural constraint". Another barrier faced by women who may want to use bike share schemes "family responsibilities", as caring for children and other members of the family prevents women from using bicycles $[90,108,110]$.

The fourth and last CFC for Use Case III is "weather and topography" understood as the impact of weather and the urban terrain on cycling ad therefore bike sharing. Regarding the "weather" FC, bad weather conditions, it is suggested that extreme temperatures, wind, rain, or high humidity, discourages people from using the bike sharing systems $[90,93,101,112]$. Similarly, the "topography" of the route, for example, the presence of steep hills along cycle routes, has a negative impact on cycling and is a barrier to women accessing urban bike sharing [93,103]. The use of electric bicycles could help overcome this barrier.

\subsection{Use Case IV. Employment}

The aim of this use case is to understand women's participation in job positions related to transport in order to propose measures to increase women's participation in logistics and road and rail freight transport companies. We will also develop fair corporate social responsibility protocols and new curriculum design guidelines to encourage the increased participation of women in the sector. Therefore, the final goal of this use case is to increase the percentage and level of women employed in on-site and off-site positions in the transport industry. We defined on-site jobs as those which are predominantly carried out in a single location, usually within the facilities of the company (HR personnel, warehouse operators, mechanics based in a depot, etc.), and off-site professional jobs as those that (normally) involve traveling each day (e.g., truck drivers) with little time spent in a single location.

The literature review and focus groups allowed the identification of four Level 1 FCs or CFCs and 19 FCs (see Table 5). Similar to the other use cases, after identifying the FCs, the statistical results 
showed that there are significant dependences among 174 factors that indicate which FC belong to each cluster (see Table A4 of Appendix A).

Table 4. Results of literature review for the Use Case IV: employment.

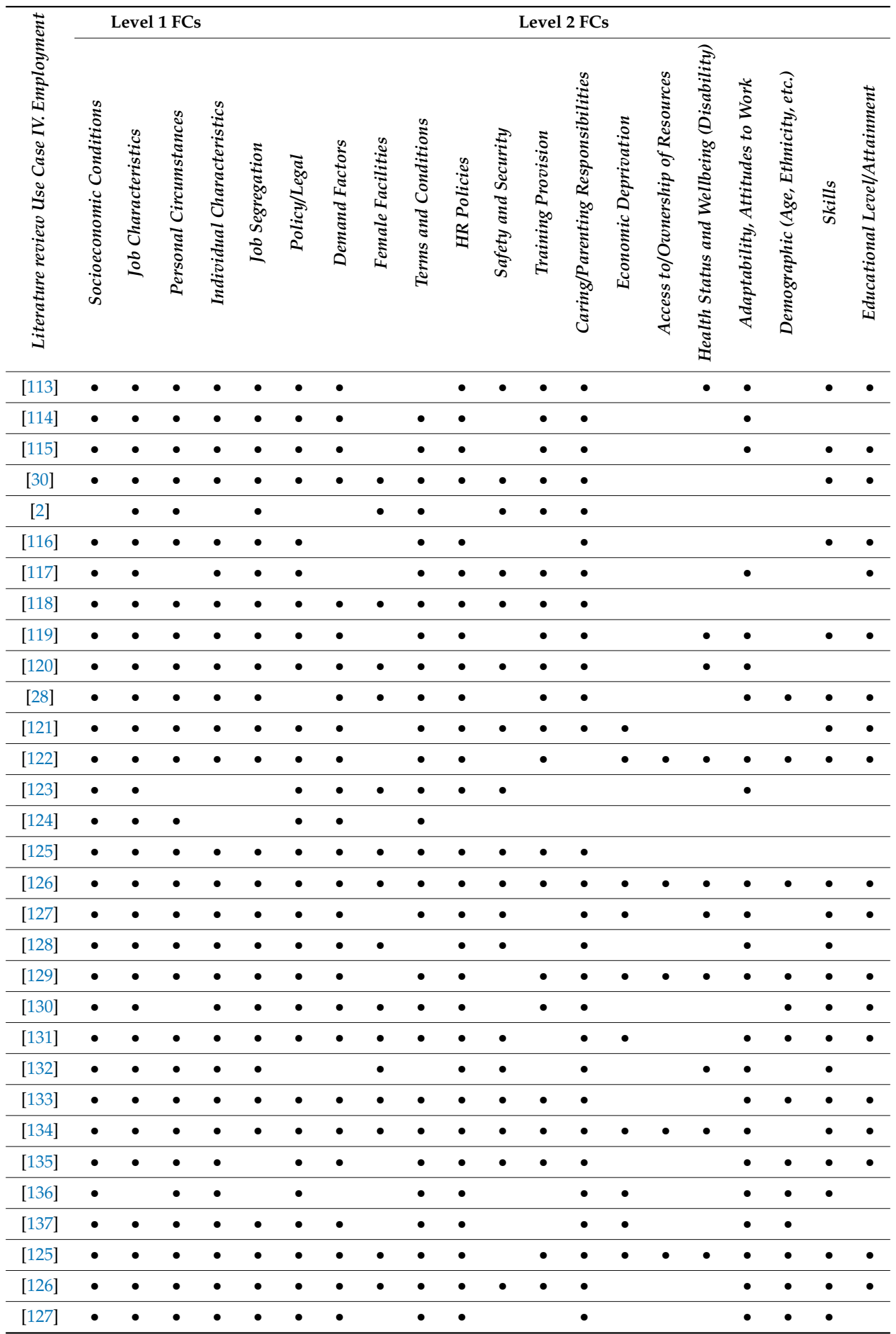


Table 5. Contingency table. Variables for the calculation of $\chi^{2}$.

\begin{tabular}{|c|c|c|c|c|}
\hline & & \multicolumn{2}{|c|}{$X$} & \multirow{2}{*}{ Total } \\
\hline & & 1 & 0 & \\
\hline \multirow{2}{*}{$\mathbf{Y}$} & 1 & $a$ & $b$ & $e=a+b$ \\
\hline & 0 & $c$ & $d$ & $f=c+d$ \\
\hline & Total & $g=a+c$ & $h=b+d$ & $n=a+b+c+d$ \\
\hline
\end{tabular}

Note: 1 indicates the papers in which the FC Y or X is mentioned and 0 the papers in which the FC $\mathrm{Y}$ or $\mathrm{X}$ is not mentioned.

Results from the statistical tests and the evaluation by the experts determined that the appropriate FCs within each cluster are the ones shown in Figure 5.

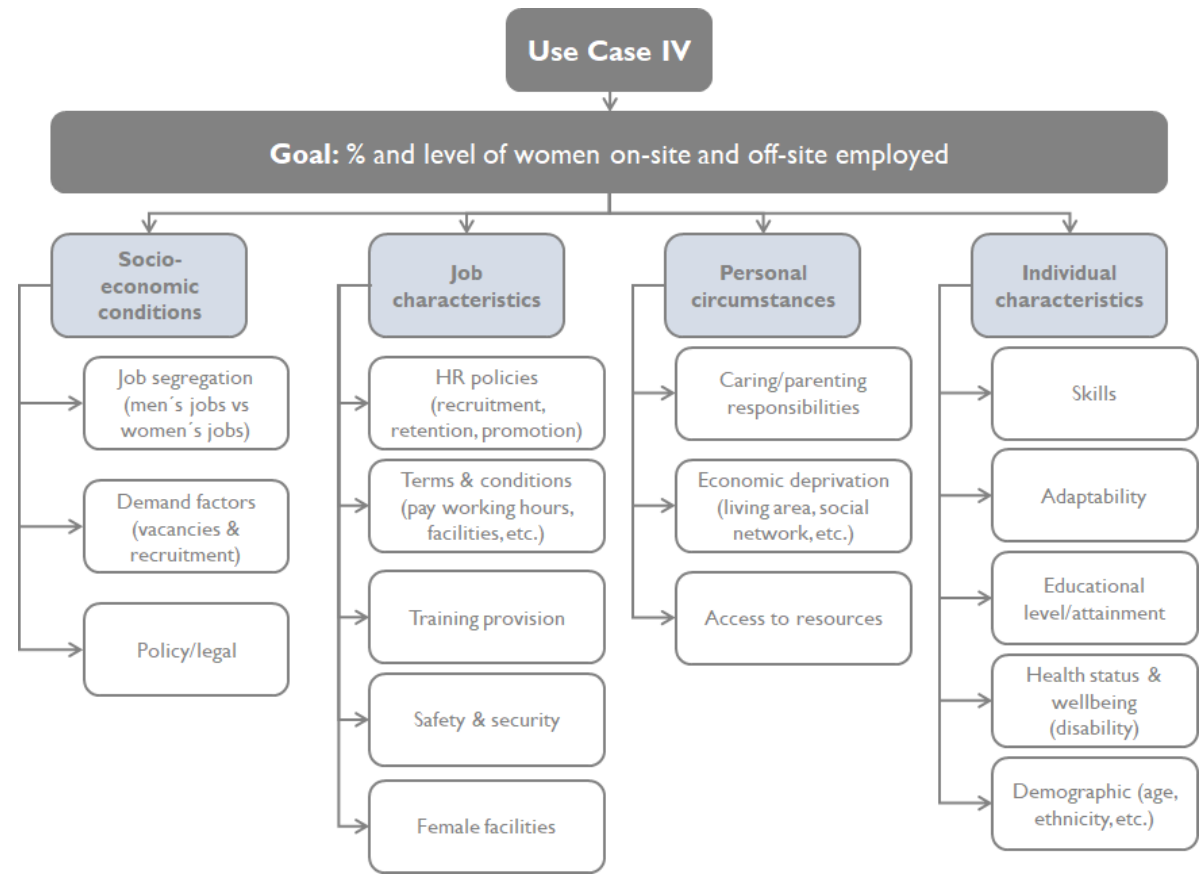

Figure 5. Hierarchy of fairness characteristics for Use Case IV.

The first CFC is related to "socioeconomic conditions". One of the main factors influencing or guiding the selection of one position above another is related to the social or historical idea that some jobs are for women and others for men-gender stereotyping. This has been defined as the "job segregation" FC, and many studies show that the transport sector is one of the most gender-segregated sectors of the economy [30]. Some measures cited in the literature to improve this aspect include school visits to attract more girls to the sector, more media representation of women in the transport sector (role models), and regularly reviewing the recruitment process for unconscious bias. The participants of the focus group sessions indicated the most important career need is equal pay between men and women for similar positions (Mean $=7, \mathrm{SD}=0.00$ ). The majority of participants in the focus group stated that they believed their gender had no impact on the kind of duties and work tasks they were expected to perform in their current role. Of those who said yes, their gender did have an impact, one participant (female) indicated that she had to undertake work duties such as administration, e.g. organizing meetings, taking minutes etc., as well as non-work, e.g. organizing cake or cards, etc. Another participant (male) indicated that men were expect to do heavier lifting and heavier manual labor than women, and were not allowed off work for their children as "we're not mums". A second FC is "demand factors", which is related to the skills and training required by the organizations and the 
training of employees, having gender neutral recruitment policies and having objective recruitment processes within the organization. New local, national, and EU policies and legislation more focused on the needs of women are required in order to increase women's participation in the transport sector; this is FC "policy/legal". Both the transport sector and transport policy makers are traditionally dominated by men and therefore center policy and plans on men's lifestyles, meaning there is little support for women in the sector and a lack of gender-sensitivity (e.g., family friendly policies, equal opportunity policies, anti-harassment, etc.). Transport systems are traditionally viewed as a male dominated sector, where many of the facilities and working conditions are those set by men and are gender biased. The development of equal employment policies for everyone is therefore necessary for fair transport related jobs, no matter the gender, ethnicity, age, disability, etc. of employees. Participants in the focus groups also indicated ethnicity as an important barrier to women entering the transport sector (Mean $=5.47, \mathrm{SD}=1.33$ ). The absence of "female facilities" (e.g., female toilets, segregated changing rooms, and suitable female personal protective equipment (PPE)) was also highlighted as a characteristic which makes it difficult to incorporate more women in transport companies $[116,120,131]$ with participants of the focus group discussing their experience of a lack of female toilets in their current employment and the need to alter company provide PPE to ensure it fits correctly.

The second CFC is "job characteristics". Developing new "HR policies" that support the fair employment of women is needed. Some of the actions to improve HR policies discussed in the literature include making jobs more attractive to women by providing paid maternity-leave, part-time job options, and ensuring a male-female ratio in both management and frontline positions. In addition, the working conditions and the environment at work are also factors that prevent women from taking jobs in the transport sector; this is what we have called the FC "terms and conditions". Since transport is still a male dominated sector, this creates a male dominated environment and fear of sexual harassment, violence, or just not being considered as an equal can prevent women from applying for transport related jobs. This indicates that the environment of work and how comfortable women feel with their colleagues can be a further factor affecting their selection of, or progression in, roles in the transport sector.

Many roles within the transport sector have long working hours that are not always family friendly, particularly in the case of certain mobile professions that require prolonged absences from home (e.g., long-distance drivers and on-board ship jobs). These working conditions can be a barrier preventing women from taking up certain roles in transport and, therefore, the "flexibility working" FC is related to the importance of organizations providing a flexible approach to working arrangements. For participants in the focus groups, having the opportunity to work from home or teleworking was considered important with an average score of 4.56 (SD 1.62), indicating a lack of flexibility as an important barrier for fair employment (Mean $=5.50, \mathrm{SD}=1.34$ ).

Within the job characteristics cluster, another important factor is the development of job-related training courses, which can increase the number of women in transport related jobs; this FC is defined as "training provision". This FC includes training courses to promote a gender equality cultural change among male colleagues, training for decision makers in relation to potentially discriminatory practices, and training for employee support (including mentoring) programs within the company for both women and men to increase their potential. Feeling safe and secure in the work environment was also highlighted as characteristic which is important for women with regards to job retention this is FC is defined as "safety and security" and includes a focus on non-consensual physical contact, sexist "jokes", or repeated sexual invitations which are considered a serious threat to the retention of female employees [120].

The third CFC is "personal circumstances". Responsibilities and a person's personal situation are also viewed as an influencing factor when choosing a job. For example, "caring/parenting responsibilities", including pregnancy, childcare, or elderly care, have a strong influence on recruitment, retention, and progression processes for women and can negatively affect their professional careers. In line with this traditional caring role for women, this has meant that many women work part time or in 
temporary work, which then leads to a lower level of income and has been defined as the FC "economic deprivation". The "residential location" of women has also been shown to be a factor which influences job selection for women, with many authors commenting that women mainly tend to find a job as near to home as possible [63]. Women with childcare responsibilities are also reported as having less available time to commute (and hence fewer job opportunities) compared to men and other women without childcare responsibilities [63]. Finally, poor accessibility to public transport, suitable timetabling, or long commuting times are factors that are considered by women when choosing a job; this is FC "access to transport".

The fourth CFC is "individual characteristics". This includes the importance of the FC "skills" for a job, understood as the specific knowledge, ability, or expertise that enables one to do something well, including productivity considerations and the availability of actions (e.g., training courses) to improve and acquire new skills for the jobs of today and those of tomorrow. Discussions in the focus groups revealed this FC to be fundamental to many participant's with regards to their intention of pursuing a career in the transport sector with one participant claiming they believed they were currently "Lacking required personality traits (e.g., assertiveness) and/or skills (e.g., communication) for my job". In addition, the inability of many women to work varying shift patterns, mainly due to caring responsibilities, is also seen as a barrier to women's employment; this is what we call the FC "adaptability". The "educational attainment" or level of education of individuals is also reported as having an influence on the level of skills, the relevance of skills to a role, and the capacity and productivity of female employees. The level and relevance of the specific skills held by female employees is directly correlated with the opportunities available to them. The work environment and the conditions experienced can affect the "health status" of people at work. Automatization of some jobs as well as actions to increase comfort at a work, including suitable personal protective equipment designed for women or benefits paid during maternity leave, can improve the conditions for women working in the transport system. Finally, FC "demographics", the place where people live, their age and culture, play a very important role in job selection. In fact, there are some economies (e.g., countries of the former Soviet Union) that, despite their largely gender-neutral legal framework, impose legal restrictions such as prohibitions on women working in certain industries and/or working at night [138].

\section{Conclusions}

The transport sector is still acknowledged as being a male dominated industry with more male employees than female. Historical, social, political, and traditionally held gender views of women as primary care givers in the family have been highlighted as some of the reasons behind gender inequality in access to and employment in the transport sector. This situation cannot be improved without the involvement of transport companies, educational establishments, and policymaking organizations implementing the additional measures required to ensure equal access to employment and transport use for both men and women are considered. These additional measures are based on sharing family care duties and providing equal opportunities for the development of women and their careers.

This paper provides data based on a thematic analysis of four distinct literature reviews and focus group discussions to determine which factors influence women's decisions in relation to their use of public transport (trains and trams) autonomous vehicles, bike sharing schemes, and their employment in the transport sector. The FCs identified were grouped within each first level FC forming clusters and analyzed using a chi-squared test $\left(x^{2}\right)$ to determine the dependencies and relationship of the different factors.

For transport infrastructures, FCs were grouped in three main pillars: accessibility of the service, design of the infrastructure, and safety and security. Aspects that influence them are the availability of the service, connection with other modes of transport, equipment such as lifts or escalators to facilitate access to the station for everyone, pickpocketing, and overcrowding. 
The analysis of autonomous vehicles showed that there are six main groups of factors influencing their acceptance and future use by women: safety and security, comfort, mobility, economy, environment, and design options.

In the case of bike sharing, four main groups of CFCs were defined that impact on women's decisions to use them: accessibility and spontaneity, safety and security, social constraints, and weather and topography. Location of docking stations, quality of the cycle infrastructure, and the availability of bikes to carry children or bags are factors influencing the women's use of bike sharing schemes.

With regards to women's employment in the transport sector, four main groups of CFCs were identified: socioeconomic conditions, job characteristics, personal circumstances, and individual characteristics. The absence of female facilities, the need for improved regulations, and the need for human resource policies which acknowledge women's caring responsibilities are some of the main factors that should be improved to increase the participation of women in transport jobs.

Further developments could be focused on applying this hierarchical model to multicriteria decision methodologies, such as the analytic hierarchy process, or to other statistical models, such as Bayesian networks, to obtain a weight for each FC and to rank them based on their weights. The identification and clustering process of the FCs addressed here, and the future possibility of ranking those FCs based on weights suggested, will make the suggestion of measures for a fairer transport system easier to evidence and therefore incorporate into existing practices.

Author Contributions: Conceptualization, G.D.M., F.E.S., A.G., and M.C.L.; Data curation, E.G.-J., S.P.-R., A.G., Y.H., A.A.-D., and M.C.L.; Formal analysis, E.G.-J., A.G., Y.H., A.A.-D., M.C.L., and F.M.; Funding acquisition, F.E.S.; Methodology, E.G.-J., S.P.-R., G.D.M., A.G., and M.C.L.; Project administration, G.D.M.; Supervision, F.E.S. and A.G.; Visualization, S.P.-R. and A.G.; Writing-original draft, E.G.-J. and S.P.-R.; and Writing-review and editing, S.P.-R. and F.E.S. All authors have read and agreed to the published version of the manuscript.

Funding: This work was supported by the H2020 program within the DIAMOND project (grant number 824326).

Acknowledgments: The authors want to thank the participation and useful inputs from the stakeholders involved in the focus group.

Conflicts of Interest: The authors declare no conflict of interest. 
Appendix A Results of the $\chi^{2}$ tests for Use Case I, Use Case II, Use Case III, and Use Case IV Literature Review

Table A1. P-value of $\chi^{2}$ for Use Case I Literature Review

\begin{tabular}{|c|c|c|c|c|c|c|c|c|c|}
\hline & $\begin{array}{c}\text { Service Availability and } \\
\text { Efficiency }\end{array}$ & $\begin{array}{l}\text { Travel and Wayfinding } \\
\text { Information Provision }\end{array}$ & $\begin{array}{l}\text { Ticketing Options } \\
\text { and Fares }\end{array}$ & $\begin{array}{c}\text { Travel } \\
\text { Purpose }\end{array}$ & $\begin{array}{c}\text { Universal } \\
\text { Design }\end{array}$ & $\begin{array}{l}\text { Cleanliness and } \\
\text { Maintenance }\end{array}$ & $\begin{array}{l}\text { Furniture and } \\
\text { Facilities }\end{array}$ & $\begin{array}{l}\text { Harassment and } \\
\text { Pickpocketing }\end{array}$ & $\begin{array}{c}\text { Overcrowding and } \\
\text { Emergency Situations }\end{array}$ \\
\hline Accessibility of the Service & $<0.01$ & 0.04 & $<0.01$ & 0.30 & 0.56 & 0.68 & 0.37 & 0.46 & 0.68 \\
\hline Design of the Infrastructure & $\underline{0.15}$ & 0.10 & 0.24 & 0.30 & $\underline{0.16}$ & 0.10 & 0.03 & $<0.01$ & 0.04 \\
\hline Safety and Security & $\frac{5.50}{0.90}$ & 0.10 & 0.24 & 0.73 & $\frac{0.16}{0.16}$ & 0.68 & 0.56 & $<0.01$ & 0.04 \\
\hline Service Availability and Efficiency & - & 0.78 & 0.22 & 0.10 & $\frac{3.54}{0.54}$ & 0.52 & 0.36 & 0.90 & 0.78 \\
\hline $\begin{array}{l}\text { Travel and Wayfinding Information } \\
\text { Provision }\end{array}$ & 0.78 & - & 0.22 & 0.81 & $\underline{0.20}$ & 0.97 & 0.05 & 0.10 & 0.97 \\
\hline Ticketing Options and Fares & 0.22 & 0.22 & - & 0.10 & 0.36 & 0.78 & 0.16 & 0.24 & 0.52 \\
\hline Travel Purpose & 0.10 & 0.81 & 0.10 & & 0.42 & 0.46 & $\frac{1.00}{1.00}$ & 0.73 & 0.81 \\
\hline Universal Design & 0.54 & 0.20 & 0.36 & 0.42 & & 0.89 & 0.29 & 0.16 & 0.11 \\
\hline Cleanliness and Maintenance & 0.52 & $\frac{0.67}{0.97}$ & 0.78 & 0.46 & 0.89 & & 0.83 & 0.68 & $\frac{0.97}{0.97}$ \\
\hline Furniture and Facilities & 0.36 & 0.05 & 0.16 & 1.00 & 0.29 & 0.83 & & 0.56 & 0.83 \\
\hline Harassment and Pickpocketing & 0.90 & 0.10 & $\overline{0.24}$ & 0.73 & 0.16 & 0.68 & 0.56 & - & 0.04 \\
\hline
\end{tabular}

significance; underline indicates statistically significant values with $20 \%$ level of significance. 
Table A2. $P$-value of $\chi^{2}$ for Use Case II Literature Review

\begin{tabular}{|c|c|c|c|c|c|c|c|c|c|c|c|c|c|c|c|c|c|c|c|c|}
\hline 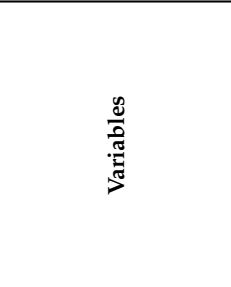 & 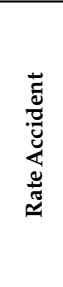 & 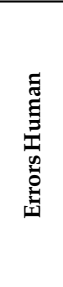 & 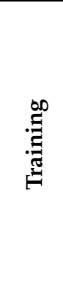 & 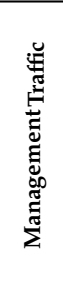 & 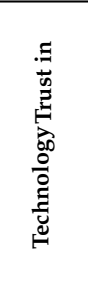 & 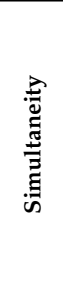 & 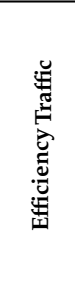 & 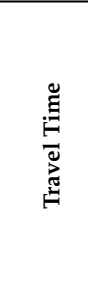 & 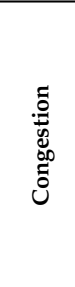 & 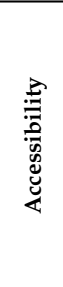 & 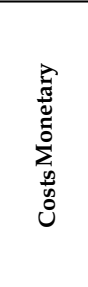 & 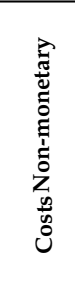 & 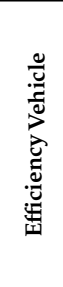 & $\begin{array}{l}\tilde{n} \\
\text { z̆ } \\
\text { z }\end{array}$ & 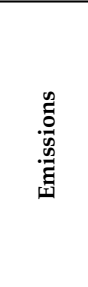 & 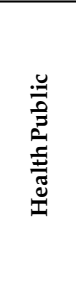 & 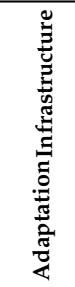 & 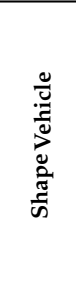 & 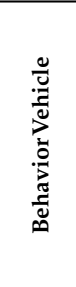 & $\sum_{I}^{E}$ \\
\hline Safety & 0.12 & 0.36 & 0.47 & 0.28 & 0.78 & 0.36 & 0.08 & 0.62 & 0.28 & 0.28 & 0.16 & 0.47 & 0.47 & 0.62 & 0.16 & 0.28 & 0.96 & 0.31 & 0.31 & 0.57 \\
\hline Comfort & $\overline{0.86}$ & 0.10 & $\underline{0.19}$ & 0.86 & $<0.01$ & 0.10 & 0.78 & 0.29 & 0.86 & 0.05 & $\overline{0.26}$ & $\underline{0.12}$ & 0.91 & 0.29 & $\overline{0.82}$ & 0.86 & 0.09 & 0.91 & 0.12 & $\underline{0.12}$ \\
\hline Mobility & 0.94 & 0.37 & $\overline{0.81}$ & 0.48 & 0.74 & 0.13 & $<0.01$ & 0.41 & 0.07 & 0.07 & 0.17 & $\overline{0.23}$ & 0.23 & 0.41 & 0.17 & 0.48 & 0.94 & 0.81 & $\overline{0.09}$ & $\overline{0.06}$ \\
\hline Economy & 0.55 & 0.21 & 0.32 & 0.06 & 0.27 & $\frac{1.00}{1.00}$ & 0.24 & $\underline{0.16}$ & $<0.01$ & 0.13 & $<0.01$ & 0.04 & 0.04 & 0.16 & 0.34 & 0.06 & 0.74 & 0.62 & 0.32 & 0.22 \\
\hline Environment & 0.74 & 0.88 & 0.72 & 0.10 & 0.92 & 0.88 & 0.08 & $\overline{0.20}$ & 0.10 & $\overline{0.59}$ & 0.01 & 0.06 & 0.72 & $\overline{0.20}$ & $<0.01$ & $<0.01$ & 0.90 & 0.72 & 0.27 & 0.01 \\
\hline Design Options & 0.35 & 0.37 & 0.81 & $\underline{0.15}$ & 0.26 & 0.13 & 0.78 & 0.25 & 0.15 & 0.07 & 0.17 & 0.81 & 0.23 & 0.25 & 0.17 & 0.48 & $<0.01$ & 0.09 & 0.09 & $<0.01$ \\
\hline Accident Rate & & 0.87 & 0.52 & $\overline{0.34}$ & 0.86 & $\overline{0.87}$ & 0.76 & $\underline{0.12}$ & $\overline{0.34}$ & 0.85 & 0.21 & 0.52 & 0.37 & 0.12 & $\overline{0.81}$ & 0.34 & 0.10 & 0.52 & 0.52 & 0.97 \\
\hline Human Errors & 0.87 & - & 0.10 & 0.43 & 0.10 & 0.51 & 0.21 & $\overline{0.71}$ & 0.43 & 0.43 & 0.31 & 0.60 & 0.60 & $\overline{0.71}$ & 0.74 & 0.43 & 0.36 & 0.60 & 0.60 & $\underline{0.14}$ \\
\hline Training & 0.52 & 0.10 & & 0.53 & 0.19 & 0.60 & 0.62 & 0.77 & 0.53 & 0.20 & 0.42 & 0.67 & 0.67 & 0.77 & 0.42 & 0.53 & 0.47 & 0.67 & 0.67 & $\overline{0.52}$ \\
\hline Traffic Management & 0.34 & 0.43 & 0.53 & - & 0.86 & 0.43 & 0.06 & 0.66 & 0.64 & 0.35 & 0.01 & 0.53 & 0.53 & 0.66 & 1.00 & 0.05 & 0.13 & 0.20 & 0.53 & 0.85 \\
\hline Trust in Technology & 0.86 & 0.10 & $\underline{0.19}$ & 0.86 & - & 0.10 & 0.78 & 0.29 & 0.86 & 0.05 & 0.26 & 0.12 & 0.91 & 0.29 & 0.82 & 0.86 & $\overline{0.09}$ & 0.91 & 0.12 & 0.12 \\
\hline Simultaneity & 0.87 & 0.51 & $\overline{0.60}$ & 0.43 & 0.10 & & 1.00 & 0.71 & 0.43 & 0.43 & 0.31 & $\overline{0.60}$ & 0.10 & 0.71 & 0.74 & 0.43 & 0.36 & 0.60 & $\overline{0.60}$ & 0.25 \\
\hline Traffic Efficiency & 0.76 & 0.21 & 0.62 & 0.06 & 0.78 & 1.00 & - & 0.49 & 0.71 & 0.71 & 0.34 & 0.62 & 0.62 & 0.49 & 1.00 & 0.46 & 0.74 & 0.62 & 0.32 & 0.22 \\
\hline Travel Time & 0.12 & 0.71 & 0.77 & 0.66 & 0.29 & 0.71 & 0.49 & - & 0.02 & 0.66 & 0.08 & $<0.01$ & 0.77 & $<0.01$ & 0.08 & 0.66 & 0.05 & 0.77 & 0.77 & 0.53 \\
\hline Congestion & $\overline{0.34}$ & 0.43 & 0.53 & 0.64 & 0.86 & 0.43 & 0.71 & 0.02 & - & 0.35 & 0.01 & 0.20 & 0.20 & 0.02 & 0.22 & 0.64 & 0.13 & 0.20 & 0.53 & 0.85 \\
\hline Accessibility & 0.85 & 0.43 & 0.20 & 0.35 & 0.05 & 0.43 & 0.71 & 0.66 & 0.35 & - & 0.22 & 0.53 & 0.53 & 0.66 & 0.22 & 0.64 & $\frac{.128}{0.28}$ & 0.53 & 0.53 & 0.17 \\
\hline Monetary Costs & 0.21 & 0.31 & 0.42 & 0.01 & 0.26 & 0.31 & 0.34 & 0.08 & 0.01 & 0.22 & - & 0.01 & 0.42 & 0.08 & 0.61 & 0.01 & 0.41 & 0.42 & 0.42 & $\overline{0.46}$ \\
\hline Non-monetary Costs & 0.52 & 0.60 & 0.67 & 0.53 & 0.12 & 0.60 & 0.62 & $<0.01$ & 0.20 & 0.53 & 0.01 & 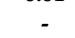 & 0.67 & $<0.01$ & 0.42 & 0.20 & 0.31 & 0.67 & 0.67 & 0.37 \\
\hline Vehicle Efficiency & 0.37 & 0.60 & 0.67 & 0.53 & 0.91 & 0.10 & 0.62 & 0.77 & 0.20 & 0.53 & 0.42 & 0.67 & - & 0.77 & 0.42 & 0.53 & 0.47 & 0.67 & 0.67 & 0.37 \\
\hline Noise & 0.12 & 0.71 & 0.77 & 0.66 & 0.29 & 0.71 & 0.49 & $<0.01$ & 0.02 & 0.66 & 0.08 & $<0.01$ & 0.77 & - & 0.08 & 0.66 & 0.05 & 0.77 & 0.77 & 0.53 \\
\hline Emissions & 0.81 & 0.74 & 0.42 & 1.00 & 0.82 & 0.74 & 1.00 & 0.08 & 0.22 & 0.22 & 0.61 & 0.42 & 0.42 & 0.08 & - & 0.22 & 0.78 & 0.42 & 0.42 & 0.07 \\
\hline Public Health & 0.34 & 0.43 & 0.53 & 0.05 & 0.86 & 0.43 & 0.46 & 0.66 & 0.64 & 0.64 & 0.01 & 0.20 & 0.53 & 0.66 & 0.22 & - & 0.83 & 0.20 & 0.53 & 0.17 \\
\hline $\begin{array}{l}\text { Infrastructure } \\
\text { Adaptation }\end{array}$ & 0.10 & 0.36 & 0.47 & $\underline{0.13}$ & 0.09 & 0.36 & 0.74 & 0.05 & $\underline{0.13}$ & 0.28 & 0.41 & 0.31 & 0.47 & 0.05 & 0.78 & 0.83 & - & $<0.01$ & $<0.01$ & 0.10 \\
\hline Vehicle Shape & 0.52 & 0.60 & 0.67 & 0.20 & 0 & 0.60 & 0 & 0 & 0 & 0.53 & 0.42 & 0.67 & 0.67 & 0.77 & 0.42 & 0.20 & $<0.01$ & - & 0.03 & 0.52 \\
\hline Vehicle Behavior & 0.52 & 0.60 & 0.67 & 0.53 & 0.12 & 0.60 & 0.32 & 0.77 & 0.53 & 0.53 & 0.42 & 0.67 & 0.67 & 0.77 & 0.42 & 0.53 & $<0.01$ & 0.03 & - & 0.02 \\
\hline HMI & 0.97 & 0.14 & 0.52 & 0.85 & 0.12 & 0.25 & 0.22 & 0.53 & 0.85 & 0.17 & 0.46 & 0.37 & 0.37 & 0.53 & 0.07 & 0.17 & 0.10 & 0.52 & 0.02 & 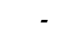 \\
\hline
\end{tabular}

Note: $p$-value $\leq 0.10$ indicates a strong relationship among FCs; $p$-value $\leq 0.2$ indicates a weak relationship among FCs. Boldface indicates statistically significant values with $10 \%$ level of significance; underline indicates statistically significant values with $20 \%$ level of significance. 
Table A3. $P$-value of $\chi^{2}$ for Use Case III Literature Review

\begin{tabular}{|c|c|c|c|c|c|c|c|c|c|c|c|c|c|c|c|c|c|c|}
\hline 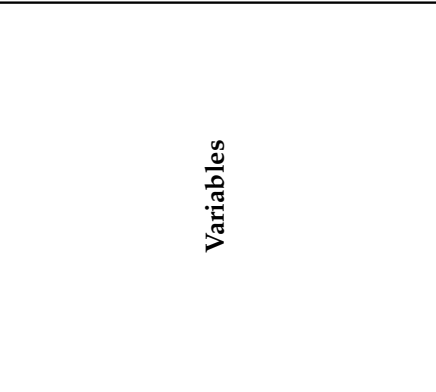 & 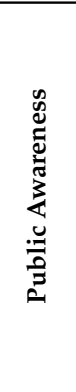 & 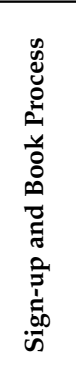 & 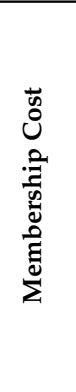 & 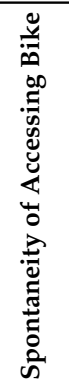 & 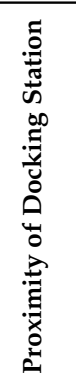 & 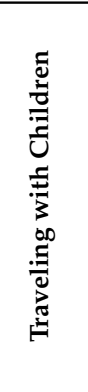 & 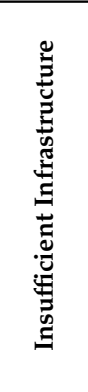 & 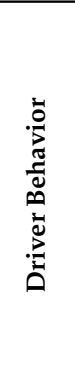 & 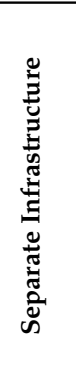 & 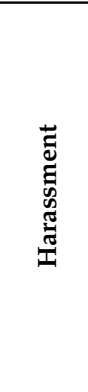 & 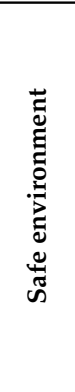 & 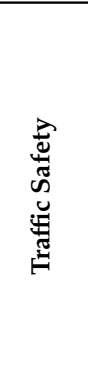 & 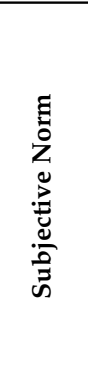 & 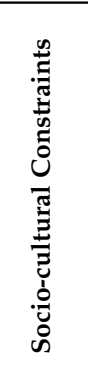 & 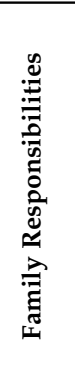 & 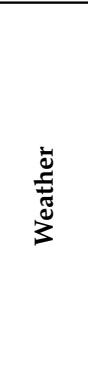 & 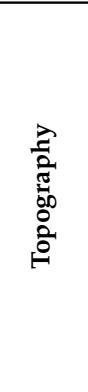 & 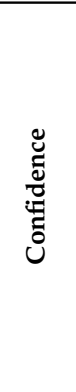 \\
\hline Accessibility and Spontaneity & 0.12 & 0.12 & 0.10 & 0.21 & 0.09 & 0.17 & 0.10 & 0.43 & 0.59 & 0.36 & 0.21 & 0.87 & 0.08 & 0.46 & 0.08 & 0.01 & 0.59 & 0.59 \\
\hline Safety and Security & $\overline{0.86}$ & $\overline{0.22}$ & 0.86 & 0.46 & 0.73 & $\overline{0.59}$ & 0.01 & 0.35 & 0.28 & 0.28 & 0.06 & $<0.01$ & 0.22 & 0.38 & 0.22 & 0.71 & 0.83 & 0.28 \\
\hline Social Constraints & 0.74 & 0.26 & $\underline{0.20}$ & 0.58 & 0.35 & $<0.01$ & 0.03 & 0.73 & 0.29 & 0.03 & 0.78 & $<0.01$ & 0.02 & $<0.01$ & 0.02 & 0.58 & 0.37 & 0.03 \\
\hline Weather and Topography & 0.12 & 0.92 & $\overline{0.08}$ & 0.39 & 0.06 & 0.25 & 0.88 & 0.10 & 0.90 & 0.05 & 0.39 & 0.74 & 0.82 & 0.92 & 0.49 & $<0.01$ & $<0.01$ & 0.39 \\
\hline Public Awareness & - & 0.41 & 0.10 & 0.58 & 0.05 & 0.48 & 0.66 & 0.38 & 0.50 & 0.50 & 0.27 & 0.86 & 0.26 & 0.97 & 0.82 & 0.27 & 0.50 & 0.50 \\
\hline Sign-up & 0.41 & - & $\underline{0.12}$ & 0.04 & 0.65 & 0.36 & 0.46 & 0.86 & 0.78 & 0.78 & 0.58 & 0.50 & 0.50 & 0.41 & 0.01 & 0.58 & 0.09 & 0.78 \\
\hline Membership Cost & 0.10 & 0.12 & $\overline{-}$ & 0.27 & 0.20 & 0.92 & 0.46 & 0.05 & 0.21 & 0.50 & 0.16 & 0.86 & 0.82 & 0.12 & 0.11 & 0.16 & 0.21 & 0.78 \\
\hline Spontaneity of Accessing Bike/Dock & 0.58 & $\overline{0.04}$ & 0.27 & - & $\overline{0.26}$ & 1.00 & 0.21 & 0.71 & 0.50 & $\underline{0.17}$ & $\overline{0.14}$ & 0.76 & 0.34 & $\overline{0.58}$ & $\overline{0.34}$ & $\overline{0.14}$ & 0.74 & 0.74 \\
\hline Proximity of Docking Station & 0.05 & 0.65 & $\underline{0.20}$ & 0.26 & - & 0.31 & 0.77 & 0.73 & 0.05 & $\overline{0.94}$ & $\overline{0.58}$ & 0.43 & $\underline{0.17}$ & 0.65 & $\underline{0.17}$ & $\overline{0.16}$ & 0.37 & 0.37 \\
\hline Traveling with Children & 0.48 & 0.36 & $\overline{0.92}$ & 1.00 & 0.31 & - & 0.17 & 0.59 & 0.90 & $<0.01$ & 0.39 & 0.14 & $\overline{<0.01}$ & 0.12 & $\overline{0.10}$ & $\overline{0.39}$ & 0.39 & $<0.01$ \\
\hline Insufficient Infrastructure & 0.66 & 0.46 & 0.46 & 0.21 & 0.77 & $\underline{0.17}$ & - & 0.43 & 0.36 & 0.36 & 1.00 & $<0.01$ & 0.31 & $\overline{0.10}$ & 0.31 & 0.21 & 0.59 & 0.36 \\
\hline Driver Behavior & 0.38 & 0.86 & 0.05 & 0.71 & 0.73 & $\overline{0.59}$ & 0.43 & - & 0.28 & 0.28 & 0.46 & 0.85 & 0.22 & 0.38 & 1.00 & 0.06 & $\underline{0.13}$ & 0.28 \\
\hline Separate Infrastructure & 0.50 & 0.78 & 0.21 & 0.50 & 0.05 & 0.90 & 0.36 & 0.28 & - & 0.96 & 0.08 & 0.12 & 0.78 & 0.50 & 0.04 & 0.74 & $\overline{0.25}$ & 0.25 \\
\hline Harassment & 0.50 & 0.78 & 0.50 & $\underline{0.17}$ & 0.94 & $<0.01$ & 0.36 & 0.28 & 0.96 & - & 0.50 & $\overline{0.12}$ & 0.04 & 0.50 & 0.41 & 0.08 & 0.21 & $<0.01$ \\
\hline Safe Environment & 0.27 & 0.58 & $\underline{0.16}$ & $\overline{0.14}$ & 0.58 & 0.39 & 1.00 & 0.46 & 0.08 & 0.50 & - & $\overline{0.55}$ & 1.00 & 0.78 & 1.00 & 0.77 & 0.50 & 0.50 \\
\hline Traffic Safety & 0.86 & 0.50 & $\overline{0.86}$ & $\overline{0.76}$ & 0.43 & 0.14 & $<0.01$ & 0.85 & 0.12 & 0.12 & 0.55 & - & 0.07 & 0.05 & 0.07 & 0.76 & 0.57 & 0.12 \\
\hline Subjective Norm & 0.26 & 0.50 & 0.82 & 0.34 & $\underline{0.17}$ & $\overline{<0.01}$ & 0.31 & 0.22 & $\overline{0.78}$ & $\overline{0.04}$ & 1.00 & 0.07 & - & 0.26 & 0.61 & 1.00 & 0.78 & $\overline{0.04}$ \\
\hline Socio-cultural Constraints & 0.97 & 0.41 & $\underline{0.12}$ & 0.58 & $\overline{0.65}$ & 0.12 & 0.10 & 0.38 & 0.50 & 0.50 & 0.78 & 0.05 & 0.26 & - & 0.03 & 0.78 & 0.78 & 0.50 \\
\hline Family Responsibilities & 0.82 & 0.01 & $\overline{0.11}$ & 0.34 & 0.17 & $\overline{0.10}$ & 0.31 & 1.00 & 0.04 & 0.41 & 1.00 & 0.07 & 0.61 & 0.03 & - & 0.34 & 0.78 & 0.04 \\
\hline Weather & 0.27 & 0.58 & $\overline{0.16}$ & 0.14 & $\overline{0.16}$ & 0.39 & 0.21 & 0.06 & 0.74 & 0.08 & 0.77 & 0.76 & 1.00 & 0.78 & 0.34 & - & 0.01 & 0.50 \\
\hline Topography & 0.50 & 0.09 & $\overline{0.21}$ & $\overline{0.74}$ & $\overline{0.37}$ & 0.39 & 0.59 & $\underline{0.13}$ & 0.25 & 0.21 & 0.50 & 0.57 & 0.78 & 0.78 & 0.78 & 0.01 & - & 0.96 \\
\hline Confidence & 0.50 & 0.78 & 0.78 & 0.74 & 0.37 & $<0.01$ & 0.36 & $\overline{0.28}$ & 0.25 & $<0.01$ & 0.50 & $\underline{0.12}$ & 0.04 & 0.50 & 0.04 & 0.50 & 0.96 & - \\
\hline
\end{tabular}

Note: $p$-value $\leq 0.10$ indicates a strong relationship among FCs; $p$-value $\leq 0.2$ indicates a weak relationship among FCs. Boldface indicates statistically significant values with $10 \%$ level of significance; underline indicates statistically significant values with $20 \%$ level of significance. 
Table A4. $P$-value of $\chi^{2}$ for Use Case IV Literature Review

\begin{tabular}{|c|c|c|c|c|c|c|c|c|c|c|c|c|c|c|c|c|}
\hline $\begin{array}{l}\frac{\mathscr{U}}{0} \\
\frac{\pi}{\pi} \\
\frac{\pi}{\pi}\end{array}$ & 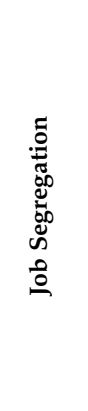 & 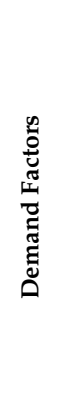 & 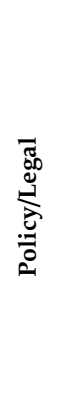 & 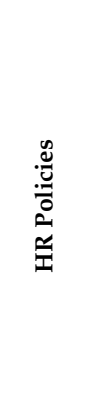 & 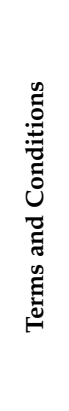 & 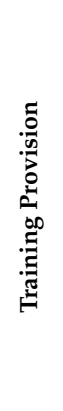 & 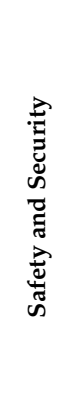 & 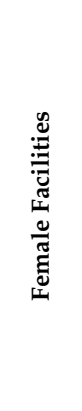 & 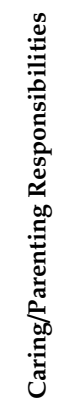 & 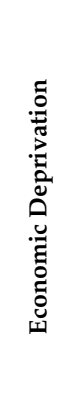 & 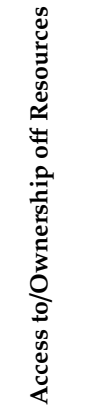 & $\frac{n}{\bar{v}}$ & 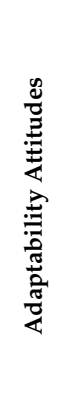 & 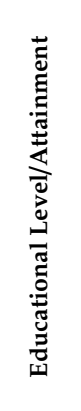 & 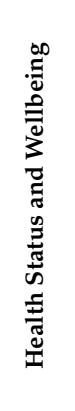 & 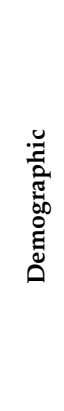 \\
\hline Socioeconomic Conditions & 0.68 & 0.02 & 0.01 & $<0.01$ & 0.72 & 0.46 & 0.40 & 0.34 & 0.76 & 0.49 & 0.64 & 0.10 & 0.08 & $\underline{0.19}$ & 0.49 & 0.43 \\
\hline Job Characteristics & $<0.01$ & $\underline{0.17}$ & 0.60 & 0.04 & 0.60 & 0.69 & 0.09 & $\underline{0.14}$ & 0.66 & 0.04 & 0.24 & 0.39 & 0.43 & $\overline{0.69}$ & 0.62 & 0.76 \\
\hline Personal Circumstances & 0.04 & $\overline{0.57}$ & 0.44 & 0.25 & 0.44 & 0.63 & 0.75 & $\overline{0.95}$ & 0.25 & 0.72 & 0.72 & 0.29 & 0.97 & 0.63 & 0.72 & 0.54 \\
\hline Individual Characteristics & $<0.01$ & 0.57 & 0.42 & $<0.01$ & 0.44 & 0.56 & 0.75 & 0.95 & $<0.01$ & 0.72 & 0.72 & 0.02 & 0.21 & 0.09 & 0.72 & 0.09 \\
\hline Job Segregation & - & 0.75 & 0.38 & 0.01 & 0.38 & 0.25 & 0.40 & $\underline{0.13}$ & 0.01 & 0.74 & 0.91 & 0.50 & 0.82 & 0.25 & 0.51 & 0.98 \\
\hline Demand Factors & 0.75 & - & 0.04 & 0.37 & 0.57 & 0.25 & 0.91 & $\overline{0.59}$ & 0.46 & 0.51 & 0.27 & 0.50 & 0.39 & 0.25 & 0.51 & 0.35 \\
\hline Policy/Legal & 0.38 & 0.04 & - & 0.25 & 0.42 & 0.56 & 0.75 & 0.33 & 0.52 & 0.72 & 0.72 & 0.92 & 0.97 & 0.56 & 0.47 & 0.66 \\
\hline HR Policies & 0.01 & 0.37 & 0.25 & - & 0.52 & 0.91 & 0.39 & 0.52 & $\underline{0.13}$ & 1.00 & 0.49 & $\underline{0.11}$ & 0.08 & 0.27 & 1.00 & $\underline{0.15}$ \\
\hline Terms and Conditions & 0.38 & 0.57 & 0.42 & 0.52 & - & 0.56 & 0.07 & 0.33 & $\overline{0.52}$ & $\underline{0.14}$ & 0.33 & $\overline{0.92}$ & 0.97 & 0.09 & 0.47 & $\overline{0.09}$ \\
\hline Training Provision & 0.25 & 0.25 & 0.56 & 0.91 & 0.56 & - & 0.52 & 0.41 & 0.27 & $\overline{0.46}$ & 0.28 & 0.83 & 0.46 & 0.05 & 0.46 & 0.85 \\
\hline Safety and Security & 0.40 & 0.91 & 0.75 & 0.39 & 0.07 & 0.52 & - & $<0.01$ & 0.39 & 0.33 & $\underline{0.20}$ & 0.53 & 0.76 & 0.95 & 0.81 & 0.08 \\
\hline Female Facilities & $\underline{0.13}$ & 0.59 & 0.33 & 0.52 & 0.33 & 0.41 & $<0.01$ & - & 0.52 & 0.23 & $\overline{0.94}$ & 0.78 & 0.49 & 0.57 & 0.64 & 0.84 \\
\hline Caring Responsibilities & $\overline{0.01}$ & 0.46 & 0.52 & $\underline{0.13}$ & 0.52 & 0.27 & 0.39 & 0.52 & - & 1.00 & 0.49 & $\underline{0.11}$ & 0.71 & 0.27 & 1.00 & 0.83 \\
\hline Economic Deprivation - & 0.74 & 0.51 & 0.72 & $\overline{1.00}$ & $\underline{0.14}$ & 0.46 & 0.33 & 0.23 & 1.00 & - & $<0.01$ & $\overline{0.10}$ & $\underline{0.16}$ & $\underline{0.13}$ & 0.01 & 0.22 \\
\hline Access/Ownership of Resources & 0.91 & 0.27 & 0.72 & 0.49 & $\overline{0.33}$ & 0.28 & $\underline{0.20}$ & 0.94 & 0.49 & $<0.01$ & - & 0.10 & $\overline{0.13}$ & $\overline{0.04}$ & $<0.01$ & $\underline{0.14}$ \\
\hline Skills & 0.50 & 0.50 & 0.92 & 0.11 & 0.92 & 0.83 & $\overline{0.53}$ & 0.78 & $\underline{0.11}$ & 0.10 & 0.10 & - & $\overline{0.10}$ & $<0.01$ & 0.10 & $\overline{0.04}$ \\
\hline Adaptability Attitudes to Work & 0.82 & 0.39 & 0.97 & 0.08 & 0.97 & 0.46 & 0.76 & 0.49 & $\frac{0.11}{0.71}$ & $\underline{0.16}$ & 0.13 & 0.10 & - & 0.37 & 0.02 & 0.08 \\
\hline Educational Level/Attainment & 0.25 & 0.25 & 0.56 & 0.27 & 0.09 & 0.05 & 0.95 & 0.57 & 0.27 & $\overline{0.13}$ & $\overline{0.04}$ & $<0.01$ & 0.37 & - & $\underline{0.13}$ & 0.21 \\
\hline Health Status and Wellbeing & 0.51 & 0.51 & 0.47 & 1.00 & 0.47 & 0.46 & 0.81 & 0.64 & 1.00 & $\overline{0.01}$ & $<0.01$ & 0.10 & 0.02 & $\underline{0.13}$ & $\overline{-}$ & 0.81 \\
\hline Demographic & 0.98 & 0.35 & 0.66 & $\underline{0.15}$ & 0.09 & 0.85 & 0.08 & 0.84 & 0.83 & 0.22 & $\underline{0.14}$ & 0.04 & 0.08 & $\overline{0.21}$ & 0.81 & - \\
\hline
\end{tabular}

Note: $p$-value $\leq 0.10$ indicates a strong relationship among FCs: $p$-value $\leq 0.2$ indicates a weak relationship among FCs. Boldface indicates statistically significant values with $10 \%$ level of significance; underline indicates statistically significant values with $20 \%$ level of significance. 


\section{References}

1. Hanson, S. Gender and mobility: New approaches for informing sustainability. Gend. Place Cult. 2010, 17, 5-23. [CrossRef]

2. Duchène, C. Gender and transport. OECD. Int. Transp. Forum. 2011, 11, 1-18.

3. Observatory: EurWORK. Final Questionnaire for EIRO Overview Report: Employment and Industrial Relations in the Railways Sector, 2012. European Foundation (Eurofound). Available online: https://www.eurofound.europa.eu/sk/publications/report/2012/final-questionnaire-for-eiro-o verview-report-employment-and-industrial-relations-in-the-railways-0 (accessed on 6 April 2020).

4. Miralles-Guasch, C.; Melo, M.M.; Marquet, O. A Gender analysis of everyday mobility in urban and rural territories: From challenges to sustainability. Gend. Place Cult. 2015, 23, 398-417. [CrossRef]

5. Hudson, C. Sharing fairly? Mobility, citizenship, and gender relations in two swedish city-regions. J. Urban Aff. 2018, 40, 82-97. [CrossRef]

6. International Transport Forum. Women's Safety and Security: A Public Transport Priority; OECD Publishing: Paris, France, 2018.

7. Mohai, P. Men, women, and the environment: An examination of the gender gap in environmental concern and activism. Soc. Nat. Resour. 1992, 5, 1-19. [CrossRef]

8. Kawgan-Kagan, I. Early adopters of carsharing with and without BEVs with respect to gender preferences. Eur. Transp. Res. Rev. 2015, 7, 33. [CrossRef]

9. Kawgan-Kagan, I.; Popp, M. Sustainability and gender: A mixed-method analysis of urban women's mode choice with particular consideration of e-carsharing. Transp. Res. Procedia 2018, 31, 146-159. [CrossRef]

10. Harvey, J.; Thorpe, N.; Caygill, M.; Namdeo, A. Public attitudes to and perceptions of high speed rail in the UK. Transp. Policy 2014, 36, 70-78. [CrossRef]

11. Emre, S.D. Assessing the effects of satisfaction and value on customer loyalty behaviors in service environments: High-speed railway in turkey as a case study. Manag. Res. Rev. 2014, 37, 706-727.

12. Haboucha, C.J.; Ishaq, R.; Shiftan, Y. User preferences regarding autonomous vehicles. Transp. Res. Part C Emerg. Technol. 2017, 78, 37-49. [CrossRef]

13. Payre, W.; Cestac, J.; Delhomme, P. Intention to use a fully automated car: Attitudes and a priori Acceptability. Transp. Res. Part F Traffic Psychol. Behav. 2014, 27, 252-263. [CrossRef]

14. Hulse, L.M.; Xie, H.; Galea, E.R. Perceptions of autonomous vehicles: Relationships with road users, risk, gender and age. Saf. Sci. 2018, 102, 1-13. [CrossRef]

15. Charness, N.; Yoon, J.S.; Souders, D.; Stothart, C.; Yehnert, C. Predictors of attitudes toward autonomous vehicles: The roles of age, gender, prior knowledge, and personality. Front. Psychol. 2018, 9, 2589. [CrossRef] [PubMed]

16. Dourado, J.F.; Pereira, A.T.; Nogueira, V. Personality and driver behaviour questionnaire: Correlational exploratory study. In Transport Infrastructure and Systems; Dell'Acqua, G., Wegman, F., Eds.; Taylor \& Francis Group: Oxfordshire, UK, 2017; pp. 787-793. ISBN 9781138030091.

17. Badstuber, N. Mind the Gender Gap: The Hidden Datagap in Transport, 2019. London Reconnections. Available online: https://www.themandarin.com.au/108874-mind-the-gender-gap-the-hidden-data-gap-in-t ransport/ (accessed on 6 April 2020).

18. Criado-Perez, C. Invisible Women: Exposing Data Bias in a World Designed for Men; Vintage Publishing: New York, NY, USA, 2019; ISBN 9781784742928.

19. Berger, R. Bike Sharing 5.0. Market Insights and Outlook. Available online: https://www.rolandberger.com/p ublications/publication_pdf/roland_berger_study_bike_sharing_5_0.pdf (accessed on 5 July 2019).

20. Fishman, E.; Washington, S.; Haworth, N.; Watson, A. Factors influencing bike share membership: An analysis of melbourne and brisbane. Transp. Res. Part A Policy Pract. 2015, 71, 17-30. [CrossRef]

21. Karki, T.K.; Tao, L. How accessible and convenient are the public bicycle sharing programs in China? Experiences from Suzhou City. Habitat Int. 2016, 53, 188-194. [CrossRef]

22. Nikitas, A. Understanding bike-sharing acceptability and expected usage patterns in the context of a small city novel to the concept: A story of 'Greek Drama'. Transp. Res. Part F Traffic Psychol. Behav. 2018, 56, 306-321. [CrossRef]

23. Stredwick, A. Why Don't More Women Cycle? 2017. Cycling UK. Available online: https://www.cyclinguk. org/article/campaigns-guide/women-cycling (accessed on 2 July 2019). 
24. Ricci, M. Bike sharing: A review of evidence on impacts and processes of implementation and operation. Res. Transp. Bus. Manag. 2015, 15, 28-38. [CrossRef]

25. Zhao, J.; Wang, J.; Deng, W. Exploring bikesharing travel time and trip chain by gender and day of the week. Transp. Res. Part C Emerg. Technol. 2015, 58, 251-264. [CrossRef]

26. OECD Data. Part-Time Employment Rate, 2018. OECD (Organization for Economic Cooperation). Available online: https://data.oecd.org/emp/part-time-employment-rate.htm (accessed on 4 July 2019).

27. Eurostat. Employment by Sex, Age and Economic Activity (from 2008 onwards, NACE Rev. 2)-1 000, 2020. European Commission. Available online: http://appsso.eurostat.ec.europa.eu/nui/show.do?dataset=lfsa_eg an2\&lang=en (accessed on 7 April 2019).

28. Women in Rail: Industry Survey. Women in Rail, 2015. Available online: http://womeninrail.org/news/wom en-in-rail-industry-survey-2/ (accessed on 8 July 2019).

29. Weingarten, T. How These Female Car Designers are Challenging Stereotypes. CNN Style, 2016. Available online: https://edition.cnn.com/style/article/female-car-designers/index.html (accessed on 8 July 2019).

30. Corral, A.; Isusi, I. Innovative Gender Equality Measures in the Transport Industry; Dublin European Foundation for the Improvement of Living and Working Conditions: Dublin, Ireland, 2007.

31. Molero, G.; Poveda-Reyes, S.; Blache, C.; Choubassi, R.; Boratto, L.; Leva, M.C.; Santarremigia, F. Structuring the evaluation of the inclusion of women within the transport sector: A use case study based on the inclusion diamond model. In Proceedings of the Transport Research Arena 2020, Helsinki, Finland, 27-30 April 2020.

32. Bowling, B. Fair and effective policing methods: Towards "Good Enough" policing. J. Scand. Stud. Criminol. Crime Prev. 2007, 8, 17-32. [CrossRef]

33. Gullo, K.; Brown, J.; Sorensen, C. Future Research Directions in Future Research Directions in Sustainable Mobility and Accessibility. Sustainable Mobility Accessibility Research and Transformation (SMART); University of Michigan: Ann Arbor, MI, USA, 2008.

34. Litman, T. Evaluating transportation equity. World Transp. Policy Pract. 2002, 8, 50-65.

35. Braun, V.; Clarke, V. Using thematic analysis in psychology. Qual. Res. Psychol. 2006, 3, 77-101. [CrossRef]

36. Pham, M.T.; Rajić, A.; Greig, J.D.; Sargeant, J.M.; Papadopoulos, A.; Mcewen, S.A. A scoping review of scoping reviews: Advancing the approach and enhancing the consistency. Res. Synth. Methods 2014, 5, 371-385. [CrossRef] [PubMed]

37. Mays, N.; Roberts, E.; Popay, J. Synthesizing research evidence. In Studying the Organisation and Delivery of Health Services: Research methods; Fulop, N., Allen, P., Clarke, A., Black, N., Eds.; Routledge: London, UK, 2001; pp. 188-219.

38. Munn, Z.; Peters, M.D.J.; Stern, C.; Tufanaru, C.; McArthur, A.; Aromataris, E. Systematic review or scoping review? Guidance for authors when choosing between a systematic or scoping review approach. BMC Med. Res. Methodol. 2018, 18, 143. [CrossRef] [PubMed]

39. Arksey, H.; O'Malley, L. Scoping studies: Towards a methodological framework. Int. J. Soc. Res. Methodol. 2005, 8, 19-32. [CrossRef]

40. Sheskin, D.J. Handbook of Parametric and Non Parametric Statistical Procedures, 3rd ed.; Chapman \& Hall/CRC: Boca Raton, FL, USA, 2011; ISBN 9781420036268.

41. Molero, G.D.; Santarremigia, F.E.; Poveda-Reyes, S.; Mayrhofer, M.; Awad-Núñez, S.; Kassabji, A. Key factors for the implementation and integration of innovative ict solutions in smes and large companies involved in the multimodal transport of dangerous goods. Eur. Transp. Res. Rev. 2019, 11, 1-16. [CrossRef]

42. Santarremigia, F.E.; Molero, G.D.; Poveda-Reyes, S.; Aguilar-Herrando, J. Railway safety by designing the layout of inland terminals with dangerous goods connected with the rail transport system. Saf. Sci. 2018, 110, 206-216. [CrossRef]

43. Vaidya, O.S.; Kumar, S. Analytic hierarchy process: An overview of applications. Eur. J. Oper. Res. 2006, 169, 1-29. [CrossRef]

44. Ghorbanzadeh, O.; Moslem, S.; Blaschke, T.; Duleba, S. Sustainable urban transport planning considering different stakeholder groups by an interval-AHP decision support model. Sustainability 2018, 11, 9. [CrossRef] 
45. Albeniz, A.; Alonso, A. Debate and Criteria for Assistance from the Perspective of Genre for Getxo. Analysis and Proposal of Sensitive Points Detected by the Participants Workshops Forbidden City Map; HIRIA Kolektiboa: Bilbao, Spain, 2009.

46. Millenials \& Mobility: Understanding the Millenial Mindset. APTA (American Public Transport Association). 2013. Available online: https://www.apta.com/wp-content/uploads/Resources/resources/reportsandpublicat ions/Documents/APTA-Millennials-and-Mobility.pdf (accessed on 6 April 2020).

47. Asian Development Bank. Gender Tool Kit : Transport. Maximizing the Benefits of Improved Mobility for All; ADB: Metro Manila, Philippines, 2013; ISBN 9789292541453.

48. European Charter for Women in the City. Moving towards a Gender-Conscious City; 1994. European Commission. Available online: http://www.hlrn.org/img/documents/1994-EuropeanCharterf orWomenintheCity.pdf (accessed on 6 April 2020).

49. Ella se Mueve Segura-She Moves Safely, 2017. FIA Foundation. Available online: https://www.fiafoundati on.org/connect/publications/ella-se-mueve-segura-she-moves-safely (accessed on 6 April 2020).

50. Gheorghiu, R.; Dragomir, B.; Andreescu, L.; Cuhls, K.; Rosa, A.; Curaj, A.; Weber, M. New Horizons: Data from a Delphi Survey in Support of European Union Future Policies in Research and Innovation; Directorate-General for Research and Innovation; European Commission; Publications Office of the European Union: Luxemburg, 2017; ISBN 9789279764523.

51. Madriaza, P.; Monnier, C.; Ponsot, A.-S.; Lemaire, P.-A.; Travers, K.; Shaw, M.; Hernandez, S. Crime Prevention and Community Safety: Cities and the New Urban Agenda; Madriaza, P., Shaw, M., Eds.; International Centre for the Prevention of Crime: Montréal, QC, Canada, 2016; ISBN 9782921916899.

52. Loukaitou-Sideris, A. Fear and safety in transit environments from the women's perspective. Secur. J. 2014, 27, 242-256. [CrossRef]

53. MacLeod, P.; Dudleston, A.; Barham, P.; Rye, T. Improved Public Transport for Disabled People; Government Social Research: Edinburgh, UK, 2006; ISBN 0-7559-6032-7.

54. Station Capacity. Assessment Guidance, 2011. Network Rail: London. Available online: https://cdn.networ krail.co.uk/wp-content/uploads/2019/03/Station-capacity-planning-guidance.pdf (accessed on 6 April 2020).

55. Peters, D. Gender and Sustainable Urban Mobility, 2013. Global report on Human Settlements 2013: Thematic Report Gender, Nairobi. Available online: https:/civitas.eu/sites/default/files/unhabitat_gender_su rbanmobilitlity_0.pdf (accessed on 6 April 2020).

56. Shrestha, B.P.; Millonig, A.; Hounsell, N.B.; McDonald, M. Review of public transport needs of older people in european context. J. Popul. Ageing 2017, 10, 343-361. [CrossRef]

57. Soltani, S.H.K.; Sham, M.; Awang, M.; Yaman, R. Accessibility for disabled in public transportation terminal. Procedia Soc. Behav. Sci. 2012, 35, 89-96. [CrossRef]

58. Suman, H.K.; Bolia, N.B. A review of service assessment attributes and improvement strategies for public transport. Transp. Dev. Econ. 2019, 5, 1. [CrossRef]

59. Thompson, K.; Hirsch, L.; Mueller, S.; Rainbird, S. A Socioeconomic Study of Carriage and Platform Crowding in the Australian Railway Industry: Final Report; CRC for Rail Innovation: Brisbane, Australia, 2012.

60. Understanding the Travel Needs of London's Diverse Communities, 2012. Transport for London. Available online: http://content.tfl.gov.uk/women.pdf (accessed on 6 April 2020).

61. Travel in London: Understanding our Diverse Communities, 2015. Transport for London. Available online: https://www.camden.gov.uk/documents/20142/18573047/3-2-9A+Clement+Combined +Evidence.pdf/2c1f40da-dd8c-d45f-af18-687735c57513 (accessed on 6 April 2020).

62. Turner, J. Urban mass transit, gender planning protocols and social sustainability-The case of Jakarta. Res. Transp. Econ. 2012, 34, 48-53. [CrossRef]

63. Grieco, M.; McQuaid, R.W. Gender and transport: An editorial introduction. Res. Transp. Econ. 2012, 34, 1-2. [CrossRef]

64. Collet, C.; Musicant, O. Associating vehicles automation with drivers functional state assessment systems: A challenge for road safety in the future. Front. Hum. Neurosci. 2019, 13, 1-12. [CrossRef] [PubMed]

65. Kuhn, A.; Carmona, J.; Novak, T.; Aigner, W.; Schildorfer, W.; Patz, D. Test fields and advanced accompanying methods as necessity for the validation of automated driving. In Proceedings of the 7th transport research arena TRA 2018, Vienna, Austria, 16-19 April 2018. 
66. Rogic, B.; Eichberger, A.; Quinz, P.; Koglbauer, I.; Haberl, M.; Malic, D. Evaluation of human acceptance and comfort of automated highway driving at different levels of automation. In Proceedings of the 7th Transport Research Arena TRA 2018, Vienna, Austria, 16-19 April 2018.

67. Meschtscherjakov, A.; Trösterer, S.; Mirnig, A.G.; Mccall, R.; Mcgee, F.; Tscheligi, M. Driver de-skilling and its effect for safety in autonomous driving. In Proceedings of the 7th Transport Research Arena TRA 2018, Vienna, Austria, 16-19 April 2018.

68. Peter, A.; Pernilla, I. A cost-benefit analysis of self-driving vehicles on the road. In Proceedings of the 7th Transport Research Arena TRA 2018, Vienna, Austria, 16-19 April 2018.

69. Nielsen, T.A.S.; Christiansen, U. Expectations towards the self-driving car: Results from a survey of use-intentions and demand responses in the adult danish population. In Proceedings of the 7th Transport Research Arena TRA 2018, Vienna, Austria, 16-19 April 2018.

70. Patz, D. I'll drive you! On the public acceptance of Autonomous Driving and its Impacts on Further Considerations in Austria and Beyond. In Proceedings of the 7th Transport Research Arena TRA 2018, Vienna, Austria, 16-19 April 2018.

71. Duy Son, T.; Awatsu, L.; Hubrechts, J.; Bhave, A.; der Auweraer, H. A simulation-based testing and validation framework for ADAS development. In Proceedings of the 7th Transport Research Arena TRA 2018, Vienna, Austria, 16-19 April 2018.

72. Blokpoel, R.; Lu, M. Cooperative systems for future automated road transport and traffic management in urban areas. In Proceedings of the 7th Transport Research Arena TRA 2018, Vienna, Austria, 16-19 April 2018.

73. Raposo, M.A.; Ciuffo, B.; Makridis, M.; Thiel, C. Transitioning towards a coordinated automated road transport (C-ART) system. In Proceedings of the 7th Transport Research Arena TRA 2018, Vienna, Austria, 16-19 April 2018.

74. Barnard, Y.; Zlocki, A.; Innamaa, S.; Gellerman, H.; Koskinen, S.; Chen, H.; Jia, D. Assessing the impact of automated driving: Needs, challenges and future directions. In Proceedings of the 7th Transport Research Arena TRA 2018, Vienna, Austria, 16-19 April 2018.

75. Pereira, E.; Costa, S.; Costa, N.; Arezes, P. Wellness in cognitive workload-A conceptual framework. In Advances in Intelligent Systems and Computing, Proceedings of the AHFE 2018 International Conference on Human Factors and Systems Interaction, Orlando, FL, USA, 21-25 July 2018; Ayaz, H., Mazur, L., Eds.; Springer International Publishing: Cham, Switerland, 2019; Volume 775, pp. 353-364. ISBN 978-3-319-94865-2.

76. Schwarz, C.; Gaspar, J.; Brown, T. The effect of reliability on drivers' trust and behavior in conditional automation. Cogn. Technol. Work 2019, 21, 41-54. [CrossRef]

77. Schieben, A.; Wilbrink, M.; Kettwich, C.; Madigan, R.; Louw, T.; Merat, N. Designing the interaction of automated vehicles with other traffic participants: Design considerations based on human needs and expectations. Cogn. Technol. Work 2019, 21, 69-85. [CrossRef]

78. Brell, T.; Philipsen, R.; Ziefle, M. sCARy! Risk perceptions in autonomous driving: The influence of experience on perceived benefits and barriers. Risk Anal. 2019, 39, 342-357. [CrossRef]

79. Diels, C.; Erol, T.; Kukova, M.; Wasser, J.; Cieslak, M.; Miglani, A.; Mansfield, N.; Hodder, S.; Bos, J. Designing for comfort in shared and automated vehicles (SAV): A conceptual framework. In Proceedings of the 1st International Comfort Congress (ICC), Salerno, Italy, 7-8 June 2017.

80. Jugade, S.C.; Victorino, A.C.; Cherfaoui, V.B.; Kanarachos, S. Sensor based prediction of human driving decisions using feed forward neural networks for intelligent vehicles. In Proceedings of the 2018 21st International Conference on Intelligent Transportation Systems (ITSC), Maui, HI, USA, 4-7 November 2018; pp. 691-696.

81. Hohenberger, C.; Spörrle, M.; Welpe, I.M. How and why do men and women differ in their willingness to use automated cars? The influence of emotions across different age groups. Transp. Res. Part A Policy Pract. 2016, 94, 374-385. [CrossRef]

82. Kyriakidis, M.; Happee, R.; De Winter, J.C.F. Public opinion on automated driving: Results of an international questionnaire among 5000 respondents. Transp. Res. Part F Traffic Psychol. Behav. 2015, 32, 127-140. [CrossRef]

83. Shergold, I.; Wilson, M.; Parkhurst, G. The Mobility of Older People, and the Future Role of Connected Autonomous Vehicles. A Literature Review. 2016. Available online: https://uwe-repository.worktribe.com/o utput/908700 (accessed on 6 April 2020). 
84. Olsen, T.; Sweet, M.N. Who's driving change? Potential to commute further using automated vehicles among existing drivers in southern Ontario, Canada. Transp. Res. Rec. J. Transp. Res. Board 2019, 2673, 1-12. [CrossRef]

85. Hand, S.; Lee, Y.-C. Who would put their child alone in an autonomous vehicle? Preliminary look at gender differences. Proc. Hum. Factors Ergon. Soc. Annu. Meet. 2018, 62, 256-259. [CrossRef]

86. Pettigrew, S.; Worrall, C.; Talati, Z.; Fritschi, L.; Norman, R. Dimensions of attitudes to autonomous vehicles. Urban Plan. Transp. Res. 2019, 7, 19-33. [CrossRef]

87. Böhm, P.; Kocur, M.; Firat, M.; Isemann, D. Which factors influence attitudes towards using autonomous vehicles? In Proceedings of the 9th International ACM Conference on Automotive User Interfaces and Interactive Vehicular Applications Adjunct-Automotive UI '17, Oldenburg, Germany, 24-27 September 2017; pp. 141-145.

88. Innamaa, S.; Smith, S.; Barnard, Y.; Rainville, L.; Rakoff, H.; Horiguchi, R.; Gellerman, H. Framework for assessing the impacts of automated driving. In Proceedings of the 7th Transport Research Arena TRA 2018, Vienna, Austria, 16-19 April 2018.

89. Sadigh, D.; Sastry, S.; Seshia, S.A.; Dragan, A.D. Planning for autonomous cars that leverages effects on human actions. In Proceedings of the robotics: Science and systems conference, AnnArbor, MI, USA, 18-22 June 2016.

90. What are the Barriers to Cycling Amongst Ethnic Minority Groups and People from Deprived Backgrounds? Policy Analysis Research Summary, 2011. Transport for London. Available online: http://content.tfl.gov.uk/b arriers-to-cycling-for-ethnic-minorities-and-deprived-groups-summary.pdf (accessed on 6 April 2020).

91. Fishman, E.; Washington, S.; Haworth, N.; Mazzei, A. Barriers to bikesharing: An analysis from melbourne and brisbane. J. Transp. Geogr. 2014, 41, 325-337. [CrossRef]

92. Fishman, E.; Washington, S.; Haworth, N. Barriers and facilitators to public bicycle scheme use: A qualitative approach. Transp. Res. Part F Traffic Psychol. Behav. 2012, 15, 686-698. [CrossRef]

93. Médard de Chardon, C.; Caruso, G.; Thomas, I. Bicycle sharing system ‘success' determinants. Transp. Res. Part A Policy Pract. 2017, 100, 202-214. [CrossRef]

94. McNeil, N.; Dill, J.; MacArthur, J.; Broach, J. Breaking Barriers to Bike Share: Insights from Bike Share Users. NITC-RR-884c; National Institute for Transportation and Communities: Portland, ME, USA, 2017.

95. McNeil, N.; Dill, J.; MacArthur, J.; Broach, J. Breaking Barriers to Bike Share: Insights from Residents of Traditionally Underserved Neighborhoods. NITC-RR-884b; National Institute for Transportation and Communities: Portland, ME, USA, 2017. [CrossRef]

96. Howland, S.; McNeil, N.; Broach, J.; Rankins, K.; MacArthur, J.; Dill, J. Breaking Barriers to Bike Share: Insights on Equity from a Survey of Bike Share System Owners and Operators. NITC-RR-884a; National Institute for Transportation and Communities: Portland, ME, USA, 2017. [CrossRef]

97. McNeil, N.; Dill, J.; MacArthur, J.; Broach, J.; Howland, S. Breaking Barriers to Bike Share. Insights on Equity; Transportation Research and Education Center (TREC), National Institute for Transportation and Communities (NITC): Portland, ME, USA, 2017.

98. Public Bike Share Users Survey Results 2017, 2017. Bikeplus: Leeds, UK. Available online: https://co mo.org.uk/wp-content/uploads/2018/06/Public-Bike-Share-User-Survey-2017-A4-WEB-1.pdf (accessed on 6 April 2020).

99. Cornish Jones, L. Engaging More Women in Bicycling. Key Steps and Best Practices to Improve and Advance Women's Specific Bicycle Advocacy. League of American Bicyclists, 2015. Available online: http: //bikeleague.org/sites/default/files/Womens_Outreach_Report_WABA_web.pdf (accessed on 6 April 2020).

100. Mateo-Babiano, I.; Tang, Q.; Gaabucayan-Napalang, S.; Tiglao, N. Factors that Influence Women's Participation in Public Bicycle-Sharing Programs: A Critical Review. In Proceedings of the 12th Conference of Eastern Asia Society for Transportation Studies, Ho Chi Minh, Vietnam, 18 September 2017; Volume 11.

101. Campbell, A.A.; Cherry, C.R.; Ryerson, M.S.; Yang, X. Factors influencing the choice of shared bicycles and shared electric bikes in Beijing. Transp. Res. Part C Emerg. Technol. 2016, 67, 399-414. [CrossRef]

102. Faghih-Imani, A.; Eluru, N.; El-Geneidy, A.M.; Rabbat, M.; Haq, U. How land-use and urban form impact bicycle flows: Evidence from the bicycle-sharing system (BIXI) in montreal. J. Transp. Geogr. 2014, 41, 306-314. [CrossRef] 
103. Zanotto, M. Facilitators and Barriers to Public Bike Share Adoption and Success in a City with Compulsory Helmet Legislation: A Mixed-Methods Approach. Master's Thesis, Simon Fraser University, Bunarby, BC, Canada, 21 August 2014.

104. Berger, B.; Reback, M.; Palmatier, S.M. Addressing the Barriers to Bicycling: A Bike Access Program in Lewiston and Auburn, ME. Available online: https://scarab.bates.edu/cgi/viewcontent.cgi?article=1045\&cont ext=community_engaged_research (accessed on 6 April 2020).

105. McNeil, N.; Broach, J.; Dill, J. Breaking barriers to bike share: Lessons on bike share equity. ITE J. 2018, 88, 31-35.

106. Duncan, S.; Chachra, A.; Prakash, A.; Prati, F. Global Street Design Guide; Island Press: New York, NY, USA, 2016; ISBN 978-1-61091-494-9.

107. Clark, J.; Curl, A. Bicycle and car share schemes as inclusive modes of travel? A socio-spatial analysis in glasgow, UK. Soc. Incl. 2016, 4, 83-99. [CrossRef]

108. Bopp, M.; Child, S.; Campbell, M. Factors associated with active commuting to work among women. Women Health 2014, 54, 212-231. [CrossRef] [PubMed]

109. Bonham, J.; Wilson, A. Bicycling and the life course: The start-stop-start experiences of women cycling. Int. J. Sustain. Transp. 2012, 6, 195-213. [CrossRef]

110. Murphy, E.; Usher, J. The role of bicycle-sharing in the city: Analysis of the Irish experience. Int. J. Sustain. Transp. 2015, 9, 116-125. [CrossRef]

111. Jin, S.T.; Kong, H.; Wu, R.; Sui, D.Z. Ridesourcing, the sharing economy, and the future of cities. Cities 2018, 76, 96-104. [CrossRef]

112. Pucher, J.; Buehler, R. Why canadians cycle more than Americans: A comparative analysis of bicycling trends and policies. Transp. Policy 2006, 13, 265-279. [CrossRef]

113. Opportunities and Constraints in Integrating Women as Employees in the Public Transport Sector of Delhi, 2014. Azad Foundation; University of Western Ontario. Available online: http://azadfoundation.com/wp-co ntent/uploads/2015/12/Gendered-constraints-in-employemnt-in-public-transport-A-Report.pdf (accessed on 6 April 2020).

114. Batac, T.; Chan, J.; DiFrancia, M.; Hartshorn, S.; Isaac, L.; Leary, C.; Robinson, E.; Sitaraman, S. Women in the San Francisco bay area transportation industry: A baseline study for future benchmarking of women in leadership roles. WTS International: San Francisco, CA, USA, 2012; Available online: https://www. wtsinternational.org/assets/84/22/WTS-SF_Glass_Ceiling_Baseline_Study_(Web_Version).pdf (accessed on 6 April 2020).

115. Colgan, F.; Johnstone, S.; Shaw, S. On the move: Women in the toronto public transport sector. In Women in Organisations; Ledwith, S., Colgan, F., Eds.; Macmillan Press Ltd: London, UK, 1996; pp. 245-277, ISBN 9780333605059.

116. How to Attract Women to the Transport Sector? European Commission: Brussels, 2018. Available online: https://ec.europa.eu/transport/sites/transport/files/2018-11-27-conference-how-attract-W omen-transport-sector-minutes.pdf (accessed on 6 April 2020).

117. European Commission. Strategy for Equality Between Women and Men 2010-2015; European Union: Brussels, Belgium, 2011; ISBN 9789279169816.

118. International Transport Workers. Women Transporting the World: An ITF Resource Book for Trade Union Negotiators in the Transport Sector; ITF Publications: London, UK, 2008.

119. French, E.; Strachan, G. Evaluating equal employment opportunity and its impact on the increased participation of men and women in the transport industry. Transp. Res. Part A Policy Pract. 2009, 43, 78-89. [CrossRef]

120. European Commission. Business case to increase female employment in transport. In Directorate-General for Transport and Mobility; EU Publications: Luxembourg, 2018; ISBN 978-92-76-00270-3.

121. Hanlon, S. Where do women feature in public transport? Women's Travel Issues. In Proceedings of the Second National Conference, Baltimore, MD, USA, 3-4 October 1996; pp. 648-662.

122. International Labour Office. A Skilled Workforce for Strong, Sustainable and Balanced Growth: A G20 Training Strategy; International Labour Organization: Geneva, Switzerland, 2010; ISBN 9789221242772. 
123. General Principles and Operational Guidelines for Fair Recruitment; International Labour Organization: Geneva, Switzerland, 5-7 September 2016. Available online: https://www.ilo.org/global/topics/labour-migra tion/projects/WCMS_536263/lang--en/index.htm (accessed on 6 April 2020).

124. International Labour Office. General Principles and Operational Guidelines for Fair Recruitment and Definition of Recruitment Fees and Related Costs; International Labour Organization-Fundamental Principles and Rights at Work Branch, Labour Migration Branch: Geneva, Switzerland, 2019; ISBN 9789221333548.

125. Kurshitashvili, N. Promoting Women's Employment in the Transport Sector. In Proceedings of the ADB Conference: Gender in Governance and Transport, Tbilisi, Georgia, 24-25 April 2018.

126. McQuaid, R.W.; Lindsay, C. The concept of employability. Urban Stud. 2005, 42, 197-219. [CrossRef]

127. European Commission. Study on a Pilot Project: Making the EU Transport Sector Attractive to Future Generations. MOVE-A1/5/2016-LOT3; 2017. Available online: https://www.panteia.com/uploads/2017/09/DG -MOVE_Study-Attractiveness-Transport_-Final-Report.pdf (accessed on 6 April 2020).

128. Anciaes, P.R. Women in transportation. In Encyclopedia of Transportation: Social Science and Policy; Garrett, Ed.; SAGE Publications: Shozende Oaks, CA, USA, 2014; pp. 1727-1730.

129. Sicard, S. Female truck drivers: Negotiating identity in a male dominated environment. GVSU McNair Sch. J. 2012, 16, 49-57.

130. Tanis, J. Women in transport. In Proceedings of the Polis Annual Conference 2018, Machester, UK, 22-23 November 2018.

131. Turnbull, P. Promoting the Employment Women in the Transport Sector-Obstacles and Policy Options; International Labour Organization: Geneva, Switzerland, 2013; ISBN 9789221282433.

132. Madgavkar, A.; Manyika, J.; Krishnan, M.; Ellingrud, K.; Yee, L.; Woetzel, J.; Chui, M.; Hunt, V.; Balakrishnan, S. The Future of Women at Work. Transitions in the Age of Automation; McKinsey Global Institute: San Francisco, CA, USA, 2019; Available online: https://www.mckinsey.com/ \{\}/media/McKinsey/FeaturedInsights/GenderEquality /ThefutureofwomenatworkTransitionsintheageofautomation/MGI-The-future-of-women-at-work-Exec-su mmary.ashx (accessed on 7 April 2020).

133. Miani, C.; Hoorens, S. Parents at Work: Men and Women Participating in the Labour Face. Short Statistical Report No. 2; European Union, 2014. Available online: https://www.rand.org/pubs/research_reports/RR348 .html (accessed on 7 April 2020).

134. Lee, S.; McCann, D.; Messenger, J.C. Working Time Around the World: Trends in Working Hours, Laws and Policies in a Global Comparative Perspective; Routledge: Geneva, Switzerland, 2007; ISBN 0203945212.

135. Lodovici, M.; Orlando, N.; Loi, D.; Drufuca, S.M.; Orlando, N.; Pesce, F.; Greve, B.; Eydoux, A.; Grabarek, M.; Przybysz, I.; et al. Discrimination and Access to Employment for Female Workers with Disabilities; Hamers, L., Ed.; European Union: Brussels, Belgium, 2017; ISBN 978-92-846-1237-6.

136. I international transport workers' federation-ITF. Women Bus Workers Driving to Equality: A Best Practice Guide for Road Transport Unions; International Transport Workers' Federation: London, UK, 2013; ISBN 1-904676-25-1.

137. Advancing Women in Transport. Women in Transport. Available online: https://www.womenintransport.c om/ (accessed on 29 November 2019).

138. Kurshitashvili, N.; Isik, G. Lifting Legal Barriers on Women's Employment: How it Impacts Ukraine's Logistics and Transport Sector. Available online: https://blogs.worldbank.org/europeandcentralasia/lifting-1 egal-barriers-women-s-employment-how-it-impacts-ukraine-s-logistics-and-transport-sector (accessed on 3 July 2019).

(C) 2020 by the authors. Licensee MDPI, Basel, Switzerland. This article is an open access article distributed under the terms and conditions of the Creative Commons Attribution (CC BY) license (http://creativecommons.org/licenses/by/4.0/). 